\title{
The French version of the Coparenting Inventory for Parents and Adolescents (CI-PA): Psychometric properties and a cluster analytic approach
}

Grégoire Zimmermann ${ }^{\mathrm{a}}$, Jean-Philippe Antonietti ${ }^{\mathrm{a}}$, Gillian Albert Sznitman ${ }^{\mathrm{a}}$, Stijn Van Petegem ${ }^{\mathrm{a}}$, and Joëlle Darwiche ${ }^{\mathrm{a}}$

${ }^{a}$ FAmily and DevelOpment research center (FADO), Institute of Psychology, University of Lausanne, Switzerland

\section{Corresponding author}

Grégoire Zimmermann, FAmily and DevelOpment Research Center (FADO), Institute of Psychology, University of Lausanne, Geopolis, CH-1015 Lausanne, Switzerland, E-mail: Gregoire.Zimmermann@unil.ch, Phone: +41 216923260

This article may not exactly replicate the final version published in the journal. The final version is currently "in press" in Journal of Family Studies.

The exact reference is: Zimmermann, G., Antonietti, J.-P., Albert Sznitman, G., Van Petegem, S., \& Darwiche, J. (in press). The French version of the coparenting inventory for parents and adolescents (CIPA): psychometric properties and a cluster analytic approach, Journal of Family Studies. doi: 10.1080/13229400.2020.1749714 


\begin{abstract}
Coparenting refers to the way in which adults work together in their role as parents to meet the needs of their children. Over the past decades, there has been a considerable growth of empirical research on coparenting, including the development of self-report questionnaires. However, most available measures relied exclusively on parental self-reports and were designed for use with families with toddlers or preschoolers. The aim of this study was to examine the psychometric properties of the French version of the Coparenting Inventory for Parents and Adolescents (CI-PA) and to identify coparenting profiles in a sample of 312 families with adolescents. The three-factor structure was generally replicated by CFA. Cronbach's alphas and item-total correlations revealed that the CI-PA and its subscales (cooperation, conflict and triangulation) have reasonable to good internal consistency. Convergent and discriminant construct validity of the CI-PA was confirmed, using a confirmatory factor analysis approach to multitrait (i.e., coparenting dimensions) multimethod (i.e., different informants) design. Additionally, the associations between coparenting dimensions, parenting (i.e., responsiveness, autonomy-support, psychological control), and adolescents' psychosocial adjustment (i.e., self-esteem and risk-taking) supported concurrent validity. Finally, cluster analysis identified three different profiles of coparenting in families with adolescents. Limitations and implications for future research are discussed.
\end{abstract}

KEYWORDS: Adolescence, CI-PA, coparenting, multi-informant, multitrait multimethod approach, parents. 


\section{Introduction}

The experience of raising a child is often a momentous and joyful time in the lives of parents. However, parenthood is also challenging and usually involves a reorganization at the individual and couple level. At the couple level, when adults become parents, they experience or share a new coparenting relationship in addition to their romantic relationship. Despite their interconnectedness, research has suggested that the coparenting relationship is more proximally and powerfully related to parenting than is partners' romantic relationship (Feinberg, 2002; McHale, 2010). Coparenting, in its broadest sense, is the "shared activity undertaken by those adults responsible for the care and upbringings of children” (McHale \& Irace, 2011, p. 16). More specifically, the coparental relationship refers to the way that parents or parental figures coordinate their parenting efforts and support each other in their parental role (Feinberg, 2003). Although in the literature, there are subtle differences in the definition of coparenting (e.g., Feinberg, 2003; Margolin, Gordis, \& John, 2001; McHale, 2007), most authors agree that coparenting is a multidimensional concept that can be conceived as an ongoing interactive, cooperative, and mutually supportive relationship that is essentially focused on childrearing obligations (Bonach, 2005; for a review see Favez \& Frascarolo, 2013). Often distinguished and studied dimensions of coparenting include cooperation, conflict and triangulation (Baril et al., 2007; Margolin et al., 2001; Teubert \& Pinquart, 2011a). Cooperation refers to parents' support and respect for one another in regards to childrearing issues, as well as the exchange of information about the child (Teubert \& Pinquart, 2011a). Conflict refers to interparental arguments or disagreements concerning childrearing including undermining one another through criticism or denigration (Margolin et al., 2001; Teubert \& Pinquart, 2011a). Finally, triangulation, derived from family system theories (Bowen, 1978; Minuchin, 1974), refers to parent-child boundary distortions. More specifically, a parent may involve a child in interparental arguments concerning childrearing issues in an effort to form a coalition between themselves and the child in order to exclude or undermine the other parent (Margolin et al., 2001; Teubert \& Pinquart, 2010, 2011a). 
To date, a large body of evidence has suggested that coparenting behaviours and representations contribute importantly and consistently to the child's functioning and psychosocial adjustment (for a review see Teubert \& Pinquart, 2010). Moreover, associations linking coparenting relationships to child adjustment typically remain in evidence after controlling for parent-child and parents' romantic relationships (McHale, 2010). However, past research has mainly focused on the early phase of family life investigating coparenting in families at the transition to parenthood (e.g., Bronte-Tinkew, Scott, Horowitz, \& Lilja, 2009; Van Egeren, 2004) or in early childhood (e.g., Belsky, Crnic, \& Gable, 1995; Favez et al., 2012), often relying on observational methods that can be time-consuming and not suitable for large samples (e.g., Darwiche, Favez, Simonelli, Antonietti, \& Frascarolo, 2015; Favez, Tissot, \& Frascarolo, 2019). In comparison, little is known about how coparenting functions within families with adolescents with only few studies having investigated the influence of coparenting on adolescent adjustment (Baril, Crouter, \& McHale, 2007; Feinberg, Kan, \& Hetherington, 2007; Riina \& McHale, 2014; Teubert \& Pinquart, 2011b). Adolescence is a moving and fascinating developmental period with dramatic changes that bring with them new challenges for parents, adolescents and families. During this transitional period when youth are confronted with a number of developmental tasks including their identity construction and a strive for independence (Blos, 1979; Erikson, 1968), positive coparenting relationships within the parental dyad may be crucial for parenting and the adolescent's development (Feinberg et al., 2007). Therefore, it is important for both research and counselling purposes to have at our disposal valid questionnaires that specifically assess coparenting in families with adolescents. The goal of this paper was to examine the psychometric properties of the Coparenting Inventory for Parents and Adolescents (CI-PA; Teubert and Pinquart, 2011a). Specifically, we tested its factorial structure, its convergent and discriminant, and its concurrent validity by examining relations with parenting dimensions and adolescents' psychosocial adjustment. Finally, because in the parenting literature typological approaches like Baumrind's (1968) have proven to be useful and heuristic, we also examined using cluster analysis whether we could distinguish coparenting typologies, as was 
previously done in families with young children (e.g., McHale, Kuersten-Hogan, Lauretti, \& Rasmussen, 2000) and whether there is concordance or discordance between typologies derived from different informants (i.e., adolescents, mothers and fathers).

\section{Coparenting in families with adolescents}

In adolescence, as youth initiate their identity development, begin their movement toward independence, are exposed to new social experiences, and test certain limits, coparenting and parenting can become more challenging for parents (Baril et al., 2007; Steinberg \& Silk, 2002). Hence, the alliance between parents (Weissman \& Cohen, 1985) and their ability to provide a positive cohesive family framework (e.g., high cooperation and agreement between them as well as low conflict and triangulation) may be of crucial importance for favourable parenting and adolescents' healthy psychosocial development and adjustment (Feinberg et al., 2007; Margolin et al., 2001; Teubert \& Pinquart, 2010). This is consistent with accounts of family systems theory forwarded by Minuchin (1974), and in line with research on the "spillover hypothesis" (Erel \& Burman, 1995) that suggests that experiences and emotions from one relationship (e.g., the quality of the coparental relationship) can spill over onto and influence other relationships (e.g., the quality of the parenting relationship), which in turn may impact the development of the youth. Of particular interest for our study was a set of previous results in families with adolescents showing that adaptive coparenting (e.g., coparental cooperation) was associated with more positive parenting (e.g., responsiveness), whereas maladaptive coparenting (e.g., coparental conflict) was associated with negative parenting (Bonds \& Gondoli, 2007; Teubert \& Pinquart, 2011b). Still in conformity with the spillover hypothesis, using longitudinal data from a sample of early adolescents, Siffert, Schwarz, and Stutz (2012) suggested that interparental conflicts reduced the quality of parenting, which, in turn, led to lower levels of adolescents' self-esteem. Specifically, regarding coparenting, Feinberg and colleagues (2007) were the first to examine in a longitudinal study the significance of one dimension of coparenting (conflict, i.e., disagreement concerning childrearing issues) for parenting and adolescent maladjustment. Their results suggested that coparenting conflict predicted 
mother's and father's negativity and adolescent antisocial behaviour over three years. These results were corroborated by the findings of Baril and colleagues (2007) highlighting that a high level of coparenting conflict was associated with a relative increase in adolescent's risk behaviour over two years. In the same vein, Teubert and Pinquart (2011b) showed that coparenting conflict is linked with less maternal responsiveness and involvement, which in turn is associated with lower levels of adolescent's life satisfaction. Surprisingly, neither triangulation nor cooperation were strongly associated with risky behaviours or life satisfaction respectively in the studies of Baril and colleagues (2007) and Teubert and Pinquart (2011b). However, Buehler and Welsh (2009) found that adolescents' triangulation into parents' interparental conflict was longitudinally related to increases in youths' internalizing symptoms.

Overall, these studies suggested that a suboptimal coparental relationship is associated with less adaptive parenting and psychosocial maladjustment in adolescents. However, despite their interest, these aforementioned studies on coparenting have certain limitations. First, these studies relied exclusively on parental self-report of coparenting, whereas the adolescents' perception of their parents' coparenting has not been taken into account. Although often overlooked, children's and adolescents' perception of coparenting in their families is a very central component of a comprehensive family and coparenting evaluation (McHale, 2010). Numerous studies have suggested that adolescents are able to report information about family processes (e.g., parenting dimensions, Van Petegem et al., 2017; family conflicts, Laursen, Coy, \& Collins, 1998; parental solicitation and control, Keijsers, Branje, VanderValk, \& Meeus, 2010) and that perceptual differences on family processes between parents and their adolescents (i.e., parent-adolescent discrepancies) have important implications for children's adjustment and for family functioning (e.g., De Los Reyes \& Kazdin, 2005; Rote \& Smetana, 2016). Second, in most of these studies, coparenting was measured using a number of different questionnaires, with these questionnaires sometimes not being specifically designed to evaluate the dimensions of coparenting (e.g., Buehler 
\& Welsh, 2009), or coparenting questionnaires developed within samples of families with toddlers, pre-schoolers, or preadolescents (e.g., Coparenting Questionnaire (CQ); Margolin et al., 2001).

In an effort to overcome these shortcomings, Teubert and Pinquart (2011a) developed the Coparenting Inventory for Parents and Adolescents (CI-PA), which exists in three parallel versions (for mothers, fathers, and adolescents) to assess the perceptions of parents (i.e., mother and father) and of teenagers, on three dimensions of coparenting (i.e., cooperation, conflict, and triangulation). Additionally, this questionnaire differentiates not only between dimensions of coparenting, but also on different targets of coparenting (i.e., mother's contributions, father's contributions, and the parental dyad). On one hand, similar to the CQ, father's and mother's contributions to coparenting are evaluated, however the CI-PA additionally evaluates the characteristics of coparenting at the dyadic level, allowing not only for the direct comparison of the perceptions of different family members (i.e., adolescent, father, and mother) but also a comparison of how the different members see the functioning of the dyad as a whole (Pinquart \& Teubert, 2015; Teubert \& Pinquart, 2011a). These multiple perspectives on both the coparenting relationship in general as well as the contribution of each parent speak to the uniqueness of the CI-PA in its ability to assess the coparenting unit unlike other existing measures of coparenting. Globally, the results of Teubert and Pinquart (2011a) evidenced satisfactory psychometric properties of the original adolescent, mother and father versions of the CI-PA. More specifically, the three-factor structure (with cooperation, conflict and triangulation as dimensions of coparenting) of the CI-PA was confirmed with reasonable to good internal consistencies of the subscales, ranging from 0.61 to 0.91 . Evidence of convergent validity was estimated by the degree to which different informants (i.e., adolescents, mothers, and fathers) agreed in their reports of coparenting, whereas divergent validity was estimated by the degree to which adolescents', mothers' and fathers' coparenting reports were distinct from parent-reported marital conflicts and adolescent-reported parental responsiveness (Teubert \& Pinquart, 2011a). Regarding convergent validity, evaluated by means of correlations, 
large correlations (i.e., around 0.50; Cohen, 1988) between the two parents' reports on the CI-PA were found, whereas the correlations between adolescents and parents' reports were weaker and considered as medium (i.e., around 0.30; Cohen, 1988). Concerning divergent validity, also evaluated by means of correlations, the results showed small to medium correlations in the expected directions between coparenting dimensions, marital conflict and parental warmth (Teubert \& Pinquart, 2011a). Finally, criterion validity was assessed through associations with adolescents' difficulties in psychosocial adjustment. The results indicated that coparenting dimensions, especially conflict and triangulation, were particularly associated with adolescent maladjustment (Teubert \& Pinquart, 2011a).

\section{The present study}

To the best of our knowledge, coparenting in adolescence, has never been evaluated in Frenchspeaking countries as a result of a lack of suitable and validated French measures. Recently, Frenchspeaking researchers provided preliminary data concerning the adaptation of McHale's coparenting scale (Frascarolo et al., 2009) and the Parental Alliance Inventory (Rouyer, Huet-Gueye, Baude, \& Mieyaa, 2015). However, these instruments only assess reports of the parental figures (mothers and fathers), and, like many other widely used questionnaires in research on coparenting, were developed within samples of families with younger children.

Thus, the purpose of the present study was mainly to translate and assess the psychometric properties of the French version of the CI-PA and to identify and describe coparenting typologies. Considering the multi-informant nature of the CI-PA, an important general focus of the study was to investigate whether the different reports diverge or converge in estimates of coparenting in the family. More specifically, we hypothesized, first, that the three-factor structure of coparenting could be confirmed for the three parallel versions (for adolescents, mothers and fathers) of the CI-PA. Second, we evaluated the internal consistency of each subscale of the CI-PA in terms of Cronbach's alpha. Third, in the present study, we aimed to extend previous research by using a multitraitmultimethod approach (MTMM; Campbell \& Fiske, 1959) to examine convergent and discriminant 
validity of the CI-PA. Convergent validity is the degree to which responses of different informants (i.e., adolescents, mothers and fathers) reporting upon the same coparenting dimension (e.g., triangulation) correspond with each other. For example, adolescent, mother and father reports of triangulation that highly correspond to each other would demonstrate good convergent validity. Discriminant validity is the degree to which coparenting dimensions have independent unique variances, and it would be demonstrated when a coparenting dimension (e.g., triangulation) has low correlations with other coparenting dimensions (i.e., cooperation and conflict) using reports of the same and different informants. Fourth, based on previous literature (Margolin et al., 2001; Teubert and Pinquart, 2011a), concurrent validity was examined by looking at the associations between coparenting dimensions and related constructs (i.e., the quality of parenting and adolescent psychosocial adjustment). Concerning the quality of parenting, we evaluated correlations with adolescents' perceptions of parenting dimensions (i.e., autonomy support, psychological control and responsiveness) widely recognized as crucial dimensions during adolescence (Steinberg \& Silk, 2002; Soenens, Vansteenkiste, \& Beyers, 2019). Theoretical accounts of the family systems theory (Minuchin, 1974) and the spillover hypothesis (Erel \& Burman, 1995) suggest that coparenting, even if conceptually related, can be distinguished from parenting. As a consequence, we expected, on the one hand, moderate positive correlations between coparenting cooperation and parental responsiveness and autonomy support, and on the other hand, moderate negative correlations between cooperation and parental psychological control. Additionally, we expected that coparenting conflict and triangulation would be associated moderately positively with parental psychological control and negatively with parental responsiveness and autonomy support. Concerning adolescents' psychosocial adjustment, in line with previous findings (Baril, et al., 2007; Buehler \& Welsh, 2009; Teubert \& Pinquart, 2011a), we expected that cooperation would be positively linked with indices of adolescents' psychosocial adjustment (i.e., self-esteem), whereas conflict and triangulation would be negatively associated with these indices. Finally, we used a pattern-based 
approach $^{1}$ to identify potentially meaningful coparenting family typologies in order to better connect family psychology and coparenting research with its clinical and theoretical interests (Davies, Cummings, \& Winter, 2004; Henry, Tolan, \& Gorman-Smith, 2005). As suggested by Henry and colleagues (2005), we used a cluster-analytic approach, which is a useful method of discovering groups with similar characteristics, and which is fundamentally exploratory in nature (Kaufman \& Rousseeuw, 2009; Whiteman, \& Loken, 2006). Our cluster analysis was based on adolescents', mothers', and fathers' reports on the coparenting dimensions to investigate whether a typology of coparenting in families with adolescents was empirically identifiable. Additionally, as parents and adolescents may diverge in their reports of family functioning (e.g., Rote \& Smetana, 2016; Van Petegem, Antonietti, Eira Nunes, Kins, \& Soenens, 2020), we also explored whether the identified cluster groups based on adolescents', mothers' and fathers' accounts were related to each other.

\section{Method}

\section{Participants and procedure}

Participants were drawn from the first wave of a longitudinal study on parent-adolescent relationships and identity development in the French-speaking part of Switzerland. In autumn 2015, students in their last year of mandatory school (i.e., 9th grade) from 10 randomly selected public state schools and their parents (i.e., cluster sampling strategy) were invited to participate in the study. Adolescents completed self-report questionnaires during a school period in the presence of two trained members of the research team. Adolescents brought parent surveys home with them and parents were asked to complete the questionnaire independently and send it back to the university with a pre-paid envelope. For this study, we used a subsample of 312 families for whom complete data were available (i.e., adolescent, mother, and father; $28.2 \%$ of the sample at the first wave of the study). Adolescents were 13 to 16 years old $(M=14.92, S D=0.56 ; 58.3 \%$ of girls). The

\footnotetext{
${ }^{1}$ In the literature, person-centered is generally used to designate pattern-based classification techniques. Given that the unit of the analyses in this study is at the family level (i.e, coparenting) we have preferred the adjective pattern-based rather than person-based to describe the classification techniques.
} 
average age for mothers and fathers was 46.20 years $(S D=4.61)$ and 49.37 years $(S D=5.26)$, respectively. Regarding family organization and living arrangements, the majority of adolescents were living with both natural parents ( $88 \%$ ), $6.8 \%$ were living in single-parent families, and $5.2 \%$ were living in blended families. The mean number of children living under the same roof was 2.29. The majority of participants were Swiss citizen (> $80 \%$ ) from the French ethno-linguistic minority ("Romands" $-22.9 \%$ of the Swiss population; OFS 2020) or from other European Union countries (mainly France, Portugal, Italy, or Spain). Finally, in $66 \%$ of the families, both parents work ${ }^{2}$ and the median gross household income ranged from CHF 104'000 to CHF 156'000 with $1.9 \%$ below CHF 56'000 and 7.3\% over CHF 208'000, which is in line with the median gross household income of families with children (respectively CHF 124'031.-, CHF 139'543.- and CHF 145'533.- in households with one child, two children and three and more children) in this area of the Frenchspeaking part of Switzerland (StatVD, 2015).

The study was in compliance with the ethical code of the Swiss Psychological Society (SPS ·SGP·SSP). Prior to data collection, in collaboration with the State department of education, passive informed consent from parents was gathered. More specifically, parents received a letter in which they were informed that their child's school would be participating in a study on parentadolescent relationships and identity development in adolescence, and that a questionnaire would be administered during school hours. If parents did not agree with their teenager's participation, they were asked to contact either their child's homeroom teacher or the school principal. The name and phone number of the principal investigator of the study was provided to parents if they required more information about the study. In class, a trained member of the research team explained all aspects of the study, including confidentiality as well as their ability to decline or to withdraw from participation at any time.

\footnotetext{
${ }^{2}$ Percentage of parents working full time was not investigated.
} 


\section{Measures}

Participants completed French versions of questionnaires, which were already available for all the scales except the CI-PA. The items of the CI-PA were translated from German to French by the first author according to the recommendations of the International Test commission (Hambleton, 2001). This translation was then discussed between the co-authors until a consensus was reached to develop a final single version of the CI-PA. A bilingual translator then back translated the French version to German. This procedure provided a German version judged equivalent in content with the original items of the CI-PA.

\section{Coparenting}

Adolescents' and parents' perceptions of coparenting were assessed using the Coparenting Inventory for Parents and Adolescents (CI-PA; Teubert \& Pinquart, 2011a), which assesses three coparenting dimensions (cooperation, conflict and triangulation). Adolescents were questioned on the three dimensions at a dyadic level (12 items consisting of 4 items for each dimension, e.g., "My parents decide together on important decisions that concern me" for cooperation), as well as about individual contributions of mothers and fathers to coparenting (13 items for each parental figure consisting of 5 items for cooperation, 4 items for conflict and 4 items for triangulation, e.g., "Before my mother allows me to do something important she talks about it with my father" for cooperation). The mother and father versions of the questionnaire included two parts: first, parents were questioned about the three dimensions of coparenting at a dyadic level (12 items consisting of 4 items for each dimension, e.g., "My partner and I talk about childrearing” for cooperation), keeping in mind the child participating in the study. Second, they were questioned about their perceptions of their partners' contributions to the coparenting relationship (e.g., "My partner informs me about important events concerning our child") (see Table 1 for sample items for each subscale). Participants (i.e., adolescents, mothers, and fathers) indicate the extent of their agreement on a fivepoint Likert scale ranging from 1 (not at all true) to 5 (completely true). 


\section{Parenting}

Adolescents completed three often-used scales assessing general dimensions of perceived parenting, that is, (1) the 7-item Responsiveness subscale of the Children's Report of Parent Behaviour Inventory (Schaefer, 1965; e.g., "My parents make me feel better after talking over my worries with them"), (2) the 7-item Autonomy Support subscale of the Perceptions of Parenting Scale (Grolnick, Deci, \& Ryan, 1991; e.g., "Whenever possible, my parents allow me to choose what to do") and (3) the 17-item Dependency-oriented and Achievement-oriented Psychological Control Scale (Mantzouranis, Zimmermann, Biermann Mahaim, \& Favez, 2012; Soenens, Vansteenkiste, \& Luyten, 2010; e.g., "My parents blames me that I longer want to do things that we used to enjoy"). Items of all subscales were rated on a 5-point Likert scale, ranging from 1 (strongly disagree) to 5 (strongly agree). Cronbach's $\alpha$ 's were .88 for responsiveness, .71 for autonomy support, and .80 and .90 for dependency-oriented psychological control and achievement-oriented psychological control, respectively.

\section{Self-esteem}

Adolescents' self-esteem was assessed using the French version of the 5-item global self-worth subscale of the Self-Perception Profile for Adolescents (SPPA, Bouffard et al., 2002; Harter, 1988). Adolescents rated the items on a 5-point Likert scale, ranging from 1 (strongly disagree) to 5 (strongly agree). Internal consistency was $\alpha=.83$.

\section{Risk behaviours}

In order to assess adolescents risk behaviours, youth were administered the French version of the revised Risk Involvement and Perception Scale (RIPS-R) (Zimmermann, 2010). Adolescents were presented twenty-eight risky activities, ranging from low-risk (e.g., not studying for school exam, riding a scooter or a motorcycle) to high-risk (e.g., using drugs, drunk driving, having sex without a condom) in the area of school, leisure, health, driving, lawbreaking, and drugs. Each risk behaviour 
was rated in terms of frequency of involvement during the last 12 months, on a 5-point Likert scale (never to daily or more). Internal consistency was $\alpha=.82$.

\section{Overview of Data Analyses}

To test the factor structure of the French version of the CI-PA for each informant, Confirmatory Factor Analyses (CFAs) were conducted on the variance-covariance matrix using maximum likelihood robust (MLR) estimation through R-software 3.4.0 (R Development Core Team, 2014). We chose MLR estimation method over the ML estimation method, because it allows for nonnormality in the data (Finney \& DiStefanos, 2013). We compared two series of three nested models: a one-factor model (model 1) in which all the items loaded onto a single coparenting dimension; a two-factor model (model 2A) consisting of supportive coparenting (i.e., cooperation) and unsupportive coparenting (i.e., conflict and triangulation) and a two-factor model (model 2B) consisting of triangulation vs. a combination of cooperation and conflict, because of previous results showing fairly high correlations between conflict and cooperation and questions regarding whether conflict and cooperation should be conceptualized as two independent dimensions or opposite poles of a single dimension (Teubert \& Pinquart, 2011a, 2011b); and a three-factor model (model 3) consisting of cooperation, conflict and triangulation. We evaluated the measurement of model fit through a number of standard fit indices. The Yuan-Bentler chi-square index (YB- $\left.\chi^{2}\right)$ should be as small as possible; the comparative fit index (CFI) should be equal or greater than .90; the root mean square error of approximation (RMSEA) and the SRMR (standardized root mean square residual) should be lower than .08 (Bentler \& Bonnett, 1980; Brown, 2006; Hu \& Bentler, 1999).

Internal consistencies were assessed with Cronbach's $\alpha$, for all the subscales and as reported by each informant. Convergent and discriminant validity of the CI-PA at a dyadic level (i.e., how the different members see the functioning of the dyad as a whole) were examined using a multitrait multimethod analysis (MTMM; Campbell \& Fiske, 1959). We used a confirmatory factor analysis (CFA) to analyse the MTMM matrix (Kenny \& Kashy, 1992). The CFA approach to MTMM 
handles the trait and the method factors as latent variables and examines convergent and discriminant validity at the model level; it has the advantage of providing fit statistics, allowing for a more objective evaluation of the data (Marsh \& Hocevar, 1988). In the context of this study, trait refers to each of the coparenting dimensions (i.e., cooperation, conflict and triangulation), whereas method refers to each of the informants (i.e., adolescents, mothers and fathers). Following the approach adopted in previous studies (e.g., Hsiao, Wu, \& Yao, 2014; Renno \& Wood, 2013), we constructed a three-factor model to test for discriminant and convergent validity (see Figure 1). The circles represent latent coparenting dimensions or factors: cooperation, conflict, and triangulation. The boxes represent the measured variables for each coparenting dimensions at a dyadic level by different informants: adolescents, mothers, and fathers. The single-headed arrows from the large circles to the boxes represent factor loadings of the observed variables onto their respective latent constructs. The correlations between latent constructs are represented by curved arrows between the large circles. Error terms or unexplained variance associated with each measured variable are represented by smaller circles. We allowed error terms to correlate within informant across constructs to account for shared method variance. Each of the three latent constructs were constrained to have a variance of 1.0. The discriminant validity of traits (i.e., coparenting dimensions) was determined through model comparisons based on Chi-square differences and degrees of freedom. Thus, the three-factor model in which the three coparenting dimensions are distinguished from one another was compared with alternative two-factor models (similar to models 2A and 2B) and one-factor models (similar to model 1). Additionally, the values of AIC and BIC were used to make model comparisons. A model with lower AIC and BIC values represented a better model. The convergent validity among the informants about the three coparenting dimensions was evaluated via the factor loadings of each informant. A significant factor loading represents a substantial relation with the corresponding domain. If all factor loadings are significant, informants converge in their evaluation regarding the specific domain. Concurrent validity was evaluated via Pearson correlation coefficients. 
To identify clusters of families, we conducted separate cluster analyses on CI-PA dimensions for each informant. First, a principal component analysis (PCA) was applied to the data. That is, the data were mapped on to the new feature space, allowing for better distinguishability between the different clusters (Jolliffe, 2002). Then, scores for the dimensions were subjected to hierarchical cluster analyses using Ward's method and based on squared Euclidean distances. Solution ranging from 2 to 5 clusters were investigated. The final solution was selected based on three criteria: (a) the parsimony of the solution, (b) the sample size of each cluster, and (c) the interpretability of each cluster. Furthermore, three specific indices of cluster fit were used: the Trace W index (Friedman \& Rubin, 1967), the pseudo t2 index (Duda \& Hart, 1973) and the BallHall index (Ball \& Hall, 1965). Finally, to optimize the cluster solution, we performed an iterative k-means clustering procedure using the cluster centres produced by the hierarchical cluster analysis (Faber, 1994). Chi-square analysis was then applied to compare the coparenting cluster solutions based on adolescents', mothers', and fathers' reports.

\section{Results}

\section{Factorial validity and reliability of the CI-PA}

The results of the CFAs summarized in Table 2 indicated that the three-factor model (cooperation, conflict, triangulation) provided the best fit to the data, with one exception concerning adolescents' perception of coparenting on the dyadic level. In the latter case, a two-factor model (see Table 2; model 2B: triangulation vs. a combination of cooperation and conflict) appeared more parsimonious and not statistically significantly different from the postulated three-factor model. Factor loadings of the final model for each informant (i.e., AD, AM, AF, MD, MF, FD, FM) were statistically significant $(p<.001)$ and typically above .50 . Only, 3 out of 88 factor loadings were lower than .40 (complete data are available on request from the authors). We also tested multi-group measurement invariance across gender for the final three-factor models (i.e., boys and girls for the adolescents, mothers and fathers for the parents). We used the very strict chi-square difference test and the more 
liberal $\Delta$ CFI $<.010$ supplemented by $\triangle$ RMSEA $<.015$ (Chen, 2007; Cheung \& Rensvold, 2002). Results for the adolescents (i.e., AD, AM, AF) indicated full measurement invariance (i.e., metric, scalar and latent means invariance) across gender. Metric and scalar invariances were also established between mothers and fathers at a dyadic level (i.e., MD and FD).

We calculated Cronbach's alphas and item-total correlations to examine the internal consistency of the CI-PA subscales (see Table 1). As expected, internal consistency of the CI-PA subscales was reasonable to good, with Cronbach's alphas ranging from 0.66 to 0.90 , and item-total correlations ranging from 0.26 to 0.82 . These results are highly similar to those found in the original scale development study (alphas ranging from 0.61 to 0.91 ; Teubert \& Pinquart, 2011a).

\section{Discriminant and convergent validity}

Descriptive statistics are presented in Table 3. Results of the goodness of fit indices for the four CFA models are displayed in Table 4. The three-factor model (model D) demonstrated the best fit with a YB- $\chi^{2}(15)=18.43, n s$, a CFI $=.99$, a RMSEA $=.027(90 \%$ CI: $.000-.061)$, and $\mathrm{SRMR}=.025$. Model comparisons based on Chi-square differences and the values of the AIC and the BIC were examined to determine discriminant validity. A summary of these model comparisons is provided in Table 5. We found significant Chi-square differences between the three-factor model (model D) and the alternative models (one-factor model: Model A and two-factor models: Models B and C) demonstrating discriminant validity of traits (i.e., coparenting dimensions). The results from the CFA revealed statistically significant factor loadings of each informant onto their latent corresponding coparenting dimensions, ranging from .52 to .75 ., offering evidence for convergent validity among the informants about the three coparenting dimensions.

\section{Concurrent validity}

We calculated Pearson correlations to examine relationships between coparenting, parenting, selfesteem, and risk-taking behaviours (see Table 6). Regarding the relationships with parenting, coparenting cooperation was generally: (1) slightly to moderately positively related to perceived 
responsiveness and autonomy support, and (2) negatively associated with perceived psychological control. Conversely, coparenting conflict and triangulation were generally slightly to moderately negatively associated with perceived responsiveness and autonomy support and positively with perceived psychological control. In addition, the correlations between adolescents' perceptions of coparenting cooperation and parenting were systemically stronger (i.e., moderate) than between mother's/father's perceptions of coparenting cooperation and parenting (i.e., weak), which likely is due to a single-informant bias. Concerning the relationships with adolescent psychosocial adjustment, we found moderate correlations in the expected direction between adolescents' perceptions of the coparenting relationship and global self-esteem (see Table 6). Specifically, coparenting cooperation was positively associated with adolescents' global self-esteem, whereas coparenting conflict and triangulation were negatively associated with adolescents' global selfesteem. The correlations between parents' perceptions of the coparenting relationship and adolescents' global self-esteem were generally lower. Concerning risk behaviours, we found weak to moderate correlations between adolescents' ratings on the subscales of the CI-PA and the RIPSR. Cooperation was negatively associated with adolescents' risk behaviours, whereas coparenting conflict and triangulation were positively associated with adolescents' risk behaviours. Again, the correlations between parental ratings on the CI-PA and adolescents' risk behaviours were very weak or non-existent and mostly statistically non-significant.

\section{Empirically derived coparenting clusters}

Cluster analyses were conducted separately on CI-PA dimensions for each informant. Using a twostep procedure (i.e., hierarchical and $k$-means analyses), three clusters were identified for each informant. Figures 2, 3, and 4 present the final 3-cluster solution for adolescent, mother, and father respondents, respectively. The adolescents' cluster solution (Figure 2) explained between 9\% (AFCf) to $57 \%(\mathrm{AM}-\mathrm{Tr})$ of the variance in the coparenting dimensions, and the mothers' and fathers' cluster solutions (Figure 3 and 4) explained between 32\% (MF-Cf) to $56 \%$ (MD-Cp), and 17\% (FM-Cf) to $62 \%$ (FM-Tr) of the variance of these dimensions, respectively. 
In each figure, the distance between the cluster means and the total sample standardized mean, expressed in standard deviations, may be interpreted as an effect size (Scholte, van Lieshout, de Wit, \& van Aken, 2005). According to Cohen's (1988) conventional criteria, 0.2, 0.5, and 0.8 SDs may be interpreted respectively as a small, moderate and large effect.

Across the three informants, the first cluster, which includes the highest proportion of families (56\% for adolescent respondents, $51 \%$ for mother respondents, and $58 \%$ for father respondents - see Figures 1-3), was characterized by above average cooperation scores and low levels of conflict and triangulation. Cluster 2, including approximately one third of families (27\% for adolescent respondents, $36 \%$ for mother respondents, and $37 \%$ for father respondents), was globally characterized by moderate to high levels of triangulation, moderate levels of conflict, and average to low scores of cooperation. Finally, cluster 3 including a minority of families ( $17 \%$ for adolescent respondents, $13 \%$ for mother respondents, and $5 \%$ for father respondents) was generally characterized by high to very high levels of triangulation, moderate to very high levels of conflict, and very low levels of cooperation.

Chi-square analyses comparing the coparenting cluster classifications based on adolescents', mothers', and fathers' reports indicated that the coparenting cluster solution for adolescent respondents is linked to the coparenting cluster solution for mother respondents $\left(\chi^{2}(4)=58.12\right.$, $p<.001)$ and to the coparenting cluster solution for father respondents $\left(\chi^{2}(4)=39.11, p<.001\right)$. Additionally, the coparenting cluster solution for mother and father respondents were also associated $\left(\chi^{2}(4)=65.70, p<.001\right)$. More than half of the families $(55$ to $57 \%$ ) were assigned to the same cluster group by adolescent, mother, and father respondents. Further, weighted kappa (Cohen, 1960, 1968) for the frequency tables were .39 (adolescent and mother solutions), .33 (adolescent and father solutions) and .41 (mother and father solutions). These values indicate moderate agreement between the adolescent, mother and father cluster solutions. 


\section{Discussion}

The purpose of this study was to validate the French version of the Coparenting Inventory for Parents and Adolescents (CI-PA) in a sample of 312 families with adolescents, and to identify coparenting profiles through cluster analysis. Overall, results of the current research provides preliminary confirmation that the adolescent, mother, and father versions of the CI-PA has good psychometric properties. In addition, cluster analyses identified three different profiles of coparenting for each of the informants.

Regarding the factor structure of the CI-PA, the CFA results presented values indicative of an adequate to good model fit and generally confirmed the 3-factor structure (i.e., cooperation, conflict, and triangulation) in line with the original model proposed by Teubert and Pinquart (2011a). However, the fit indices of the French version of the CI-PA are slightly inferior to those of the original German version. Additionally, and more importantly, a two-factor model yielded a similar fit as the traditional three-factor model for the adolescent data reporting on the parental dyad (i.e., adolescents' report about coparenting at the dyadic level). This result could be explained by the high correlation $(r=-.72, p<.01)$ between adolescents' report about coparenting conflict (ADCf) and cooperation (AD-Cp), suggesting that, at a dyadic level, these two dimensions are capturing rather similar information, and that a content overlap in items between adolescent report of cooperation and conflict at the dyadic level may exist (Uliaszek, 2014). In fact, a thorough examination of the adolescent version of the CI-PA suggests that the conflict items at the dyadic level failed to tap the coparental conflict defined as the extent of parental fights or arguments over child-rearing, and are more truly and basically inverted agreement and cooperation items between parents (e.g., "My parents agree on whether to fulfil my wishes and demands or not.", "If there is a problem that concerns me, my parents find a solution together.”). However, disagreement and/or non-cooperation between parents in coparenting does not necessary have to turn into interparental conflicts or arguments, understood as intense, and aversive verbal and/or physical interactions (De Los Reyes et al., 2012). Thus, the conflict dimension of the CI-PA at the dyadic level, especially in 
the adolescent version, could be considered as a disagreement dimension, similar to the childrearing agreement/disagreement component of Feinberg's coparenting model (2003). This argues for the potential development of a revised version of the CI-PA including more specific and well-defined conflict items (e.g., "When discussing educational issues about me, my parents fight or get into an argument.”). As for the scale's internal consistency, considering the relatively small number of items (i.e., four of five), Cronbach's alpha values were good to excellent (ranging from .70 to .90), except for adolescents' reports about conflict within the parental dyad, as it was slightly lower than the recommended cut-off $(\alpha=.66)$. However, this is highly comparable to what was previously observed in the original study (Teubert \& Pinquart, 2011a).

Using CFA to analyse the MTMM matrix, our findings provided evidence for discriminant and convergent validity. Among all analysed CFA models, the three-factor model (model D, see also Figure 1) showed the best fit, supporting discriminant validity and the empirical differentiation of the three coparenting dimensions. Additionally, our results supported the convergent validity of the CI-PA as indicated by significant factor loadings of different informants (i.e., adolescent, mother and father) within each coparenting dimension. These results extend previous work of Teubert and Pinquart (2011a) who examined convergent and discriminant validity only by means of correlations, and as far as we know, no study has examined the discriminant and convergent validity of the CI-PA with CFA MTMM analysis.

Findings from concurrent validity analyses first indicate small to moderate associations between positive coparenting and positive parenting as well as small to moderate association between more negative coparenting and negative parenting. That is, we found that parental figures perceived as more cooperative in their coparenting relationship were also perceived as being more warm, responsive and supportive of their adolescents' autonomy, whereas coparental discord and triangulation were associated with less warm, autonomy-supportive and more controlling forms of parenting. These results suggest that parents' difficulties in the coparental subsystem may impair the abilities of parents in the parent-adolescent subsystem to provide sensitive and responsive 
support. This is in line with previous results showing that coparental triangulation has been associated with a higher level of psychological control, whereas coparental cooperation has been associated with higher levels of parental responsiveness and autonomy support and a lower level of psychological control (Bonds \& Gondoli, 2007; Teubert \& Pinquart, 2011b). These associations are in accordance with family systems theory (White, Klein, \& Martin, 2014) and the spillover hypothesis suggesting that behaviour or affect from one familial subsystem (such as the coparental relationship) may transfer directly to another subsystem (such as the parent-adolescent relationship) within a family (Erel \& Burman, 1995). Results from concurrent validity analyses also show that coparenting is related to children's and adolescents' psychological adjustment. This is in line with the general conclusions of the meta-analysis of Teubert and Pinquart (2010). As expected, cooperation related positively to adolescents' self-esteem and negatively to adolescents' risk-taking, whereas conflict and triangulation were negatively associated with self-esteem and positively with risk-taking. However, as previously observed in the literature, all the associations were small to very small, suggesting that coparenting is one aspect of many interrelated ingredients of family life that may impact the psychosocial development of children and adolescents (Teubert \& Pinquart, 2010).

Finally, we tested whether there was evidence for distinct coparenting profiles and whether profiles based on adolescents', mothers', and fathers' accounts of coparenting related to each other. Overall, we found evidence for three profiles of coparenting relationships in families with adolescents, which were highly similar for all respondents. However, although the same cluster profiles were found for different respondents, they differ somewhat in cluster prevalence. The first cluster from all respondents was characterized by generally moderate levels of cooperation and low levels of conflict and triangulation. This cluster is comparable to a positive pattern of coparenting that was previously observed with toddlers in a play situation with parents by McHale and colleagues (2000) and characterized by high levels of interparental warmth and cooperation and low levels of antagonism. The second cluster was generally characterized by moderate levels of conflict 
and triangulation and average to low levels of cooperation. This pattern could be labeled as a mixed coparenting pattern and is similar to that which was previously described by Maccoby and colleagues (1990) in their typology of coparenting in divorced families. The mixed pattern identified by Maccoby and colleagues (1990) was characterized by high degree of cooperation but also by high levels of interparental conflict that may results in children witnessing and/or being involved in interparental arguments. Finally, the third cluster from all respondents was generally characterized by high levels of conflict and triangulation and very low levels of cooperation. This cluster is a negative or conflicted form of coparenting, which is also consistent with previous work (e.g., Maccoby, et al., 1990). This conflicted pattern was generally characterized by high levels of interparental disagreement and antagonism and low levels of cooperation that may lead to parenting described as parallel rather than coordinated (Amato, et al., 2011; Maccoby, et al., 1990). Interestingly, this cluster was nearly three times less prevalent among father respondents than among mother and adolescent respondents. The literature does globally suggest that the fathers tend to be less involved in the family, that there is persistent gender inequality regarding childcare responsibility (OFS, 2017), and that men are less sensitive to relational difficulties than women (Harvey, Wells \& Alvarez, 1978), all of which could potentially affect their perceptions of the coparenting relationship (especially when maladaptive). However, future research is needed to test this explicitly. Further, our findings evidenced moderate agreement between respondents' cluster solutions, suggesting that distinct family members may capture somewhat differently the coparenting profile of their family. In line with the proposition of McHale and colleagues (2000), these results indicate that future research should adopt approaches focusing on the degree of overlap between mothers', fathers', and adolescents' reports of coparenting, as the examination of perceptual convergence and divergence would be particularly useful for our understanding of family dynamics. To our knowledge, few studies have derived coparenting profiles, with those that have using mainly post-divorce situations and relying exclusively on parental reports of coparenting (e.g., Amato, et al., 2011; Beckmeyer, Coleman, \& Ganong, 2014; Maccoby, et al., 1990). One 
study did, however, take into account adolescents' point of view on coparenting and identified coparenting profiles based on parents' and adolescents' discrepancies in reports on coparenting (Teubert \& Pinquart, 2010). Their results suggested that moderate perceptual differences in coparenting between adolescents and their parents are common and normative, whereas larger perceptual differences may be an indication of family dysfunctions associated with adolescents' maladjustment (Teubert \& Pinquart, 2010).

The present results should be considered in light of several limitations. First, the large majority of respondents were living in upper-middle class intact families. We should thus be aware that participating families in our sample are generally characterized by adaptive coparenting (i.e., high level of cooperation and low level of triangulation), which is highly comparable to what was observed in other studies that have used the CI-PA (e.g., Teubert \& Pinquart, 2010; Teubert \& Pinquart, 2011a), and consequently may not be representative of all families with adolescents (OFS, 2017). Future work should therefore examine the psychometric properties of the CI-PA in more diverse family settings. Second, to obtain a more comprehensive understanding of coparenting in families with adolescents and to test convergent validity with different methods, additional direct observational methods should also be considered in future research. Third, in the assessment of perceived parenting, the adolescents did not respond separately in regard to their mothers and fathers. Thus, future research should differentiate between mothers and fathers parenting. Fourth, parenting and adolescents' psychological adjustment were only measured through adolescent selfreport. This single-informant bias has led to stronger associations between adolescents' coparenting, parenting and psychological adjustment report than the ones observed between parents' coparenting report and adolescent's parenting and psychological adjustment report. Finally, in this study, we used an exploratory pattern-based and data-driven approach (i.e., cluster analysis) to distinguish patterns of coparenting. Future studies may also consider the use of model-based methods such as Latent Profile Analysis (LPA; Nylund, Asparouhov, \& Muthen, 2007), which is an alternative approach that offers stringent statistical methods to determine the number of profiles. 
In conclusion, the present study offers evidence for good psychometric properties of the French adaptation of the CI-PA, thereby providing additional support to the usefulness of the scale, as well as cross-cultural validity for its use with families with adolescents. Considering the triadic nature of coparenting, the CI-PA is a very comprehensive instrument that allows the investigation of different targets of coparenting (e.g., dyad, mother's contributions and father's contributions) by relying upon different informants (i.e., adolescent and parents). However, depending on the research questions and context, the use of the CI-PA with only a single informant (e.g., adolescent) and/or a single target (e.g., the dyad) is conceivable. Furthermore, it is also possible, for example, to pool reports from different informants (e.g., the mother and the father) to obtain a total score for each subscale (see e.g., Láng \& Abell, 2018). However, taking into account the potential differences between the informants' reports may be particularly important, as previous literature repeatedly provided evidence for an only modest agreement between parents and their adolescent children, when reporting on relationships within families (Callan \& Noller, 1986; Rote \& Smetana, 2016). Further, research conclusions based on adolescents' reports are often quite different from those derived from parents' reports on parallel measures (De Los Reyes, 2013). Rather than doubting the validity of different family informants, such differences highlight the diversity of subjective experiences of family relationships, as well as singular sensitivity to the parenting and coparenting experiences (Korelitz \& Garber, 2016). Thus, this confirms the importance of gathering information from multiple informants and of considering adolescents' views on coparenting. This is undoubtedly a major strength of the CI-PA, which is a triadic assessment of the coparenting construct, contrary to available coparenting questionnaires mainly capturing parents' perceptions of the processes between themselves and the other parent. Therefore, informant discrepancies in perceptions of coparenting could be considered in future research as a central characteristic of the family system, as they may be informative of family functioning and relevant to adolescent psychosocial development (e.g., De Los Reyes \& Kazdin, 2005). Further research may also examine whether parents' individual (mothers and fathers) contribution to coparenting versus 
dyadic coparenting are equally associated with adolescent psychosocial development. Last but not least, further investigation is needed to examine its practical utility and routine use in clinical settings with families with adolescents.

\section{Acknowledgements}

We would like to thank the adolescents and their parents who kindly volunteered to participate in the study. We thank the principals of the schools and the "Direction de l'Enseignement Obligatoire" (DGEO) of the state of Vaud in Switzerland. We are also grateful to Marlene Barbosa for assistance with school contacts, recruitment organization and data collection and as well as Sophie Baudat, Vanessa Brumana, Kim Da Silva Fernandes, Saskia Degli-Antoni and Zoé Rosselet for assistance with data collection. Lastly, we would like to thank the two anonymous reviewers for their very helpful comments.

\section{Funding}

This work was supported by the Swiss National Science Foundation [grant number 100014_156155]. 


\section{References}

Amato, P. R., Kane, J. B., \& James, S. (2011). Reconsidering the « Good Divorce ». Family Relations, 60, 511-524. doi:10.1111/j.1741-3729.2011.00666.x

Ball, G. H., \& Hall, D. J. (1965). ISODATA: A novel method of data analysis and pattern classification. Menlo Park, CA: Stanford Research Institute.

Baril, M. E., Crouter, A. C., \& McHale, S. M. (2007). Processes linking adolescent well-being, marital love, and coparenting. Journal of Family Psychology, 21, 645-654. doi:10.1037/08933200.21 .4 .645

Baumrind, D. (1968). Authoritarian vs. authoritative parental control. Adolescence, 3(11), 255-272.

Beckmeyer, J. J., Coleman, M., Ganong, L. H. (2014). Postdivorce coparenting typologies and children's adjustment. Family Relations, 63, 526-537. doi:10.1111/j.1741-3729.2007.00466.x

Belsky, J., Crnic, K., \& Gable, S. (1995). The Determinants of coparenting in families with toddler boys: Spousal differences and daily hassles. Child Development, 66, 629-642. doi:10.2307/1131939

Bentler, P. M., \& Bonett, D. G. (1980). Significance tests and goodness of fit in the analysis of covariance structures. Psychological Bulletin, 88, 588-606. doi:10.1037/0033-2909.88.3.588

Blos, P. (1979). The adolescent passage: Developmental issues. New York, NY : International Universities Press.

Bonach, K. (2005). Factors contributing to quality coparenting: Implications for family policy. Journal of Divorce \& Remarriage, 43, 79-104. doi:10.1300/J087v43n03_05

Bonds, D. D., \& Gondoli, D. M. (2007). Examining the process by which marital adjustment affects maternal warmth: The role of coparenting support as a mediator. Journal of Family Psychology, 21, 288-296. doi:10.1037/0893-3200.21.2.288

Bouffard, T., Seidah, A., McIntyre, M., Boivin, M., Vezeau, C., \& Cantin, S. (2002). Mesure de l'estime de soi à l'adolescence: version canadienne-française du Self-Perception Profile for Adolescents de Harter. [Measuring adolescent self-esteem: A French-Canadian version of Harter's Self-Perception Profile for Adolescents.]. Canadian Journal of Behavioural Science / Revue canadienne des sciences du comportement, 34, 158-162. doi:10.1037/h0087167

Bowen, M. (1978). Family therapy in clinical practice. New York, NY: Rowman \& Littlefield Publishers, Inc.

Bronte-Tinkew, J., Scott, M. E., Horowitz, A., \& Lilja, E. (2009). Pregnancy intentions during the transition to parenthood and links to coparenting for first-time fathers of infants. Parenting, 9, 1-35. doi:10.1080/15295190802656729

Brown, T. A. (2006). Confirmatory factor analysis for applied research. New York, NY: Guilford. 
Buehler, C., \& Welsh, D. P. (2009). A process model of adolescents' triangulation into parents' marital conflict: The role of emotional reactivity. Journal of Family Psychology, 23, 167-180. doi:10.1037/a0014976

Callan, V. J., \& Noller, P. (1986). Perceptions of communicative relationships in families with adolescents. Journal of Marriage and Family, 48, 813-820. doi:10.2307/352574

Campbell, D. T., \& Fiske, D. W. (1959). Convergent and discriminant validation by the multitrait multimethod matrix. Psychology Bulletin, 56, 81-105.

Chen, F. F. (2007). Sensitivity of goodness of fit indexes to lack of measurement invariance. Structural Equation Modeling, 34, 155-175. doi:10.1080/10705510701301834

Cheung, G. W., \& Rensvold, R. B. (2002). Evaluating goodness-of-fit indexes for testing measurement invariance. Structural Equation Modeling, 9, 233-255. doi:10.1207/S15328007SEM0902_5

Cohen, J. (1960). A coefficient of agreement for nominal scales. Educational and Psychological Measurement, 20, 37-46. doi:10.1177/001316446002000104.

Cohen, J. (1968). Weighted kappa: Nominal scale agreement provision for scaled disagreement or partial credit. Psychological Bulletin, 70, 213-220. doi:10.1037/h0026256

Cohen, J. (1988). Statistical power analysis for behavioral sciences (2nd edition). Hillsdale, NJ: Erlbaum.

Davies, P. T., Cummings, E. M., \& Winter, M. A. (2004). Pathways between profiles of family functioning, child security in the interparental subsystem, and child psychological problems. Development and Psychopathology, 16, 525-550. doi:10.1017/S0954579404004651

Darwiche, J., Favez, N., Simonelli, A., Antonietti, J.-P., \& Frascarolo, F. (2015). Prenatal coparenting alliance and marital satisfaction when pregnancy occurs after assisted reproductive technologies or spontaneously. Family Relations, 64, 534-546. doi:10.1111/fare.12131

De Los Reyes, A. (2013). Strategic objectives for improving understanding of informant discrepancies in developmental psychopathology research. Development and Psychopathology, 25, 669-682. doi:10.1017/S0954579413000096

De Los Reyes, A., \& Kazdin, A. E. (2005). Informant discrepancies in the assessment of childhood psychopathology: a critical review, theoretical framework, and recommendations for further study. Psychological Bulletin, 131, 483-509. doi:10.1037/0033-2909.131.4.483

De Los Reyes, A., Thomas, S. A., Swan, A. J., Ehrlich, K. B., Reynolds, E. K., Suarez, L., ... Pabon, S. C. (2012). "It Depends on What You Mean by 'Disagree'": Differences between Parent and Child Perceptions of Parent-Child Conflict. Journal of Psychopathology and Behavioral Assessment, 34, 293-307. doi:10.1007/s10862-012-9288-3. 
Duda, R. O., \& Hart, P. E. (1973). Pattern classification and scene analysis. New York, NY: Wiley. Erel, O., \& Burman, B. (1995). Interrelatedness of marital relations and parent-child relations: a meta-analytic review. Psychological Bulletin, 118(1), 108-132.

Erikson, E. H. (1968). Identity: Youth and crisis. New York, NY: Norton.

Faber, V. (1994). Clustering and the continuous k-means algorithm. Los Alamos Science, 22, 138144.

Favez, N., \& Frascarolo, F. (2013). Le coparentage : composants, implications et thérapie [Coparenting : components, implications and therapy]. Devenir, 25(2), 73-92.

Favez, N., Lopes, F., Bernard, M., Frascarolo, F., Lavanchy Scaiola, C., Corboz-Warnery, A., \& Fivaz-Depeursinge, E. (2012). The development of family alliance from pregnancy to toddlerhood and child outcomes at 5 years. Family Process, 51, 542-556. doi:10.1111/j.15455300.2012.01419.x

Favez, N., Tissot, H., \& Frascarolo, F. (2019). Parents' representations of mother-child and fatherchild relationships as predictors of early coparenting interactions. Journal of Family Studies, 25, 199-213. doi:10.1080/13229400.2016.1230511

Feinberg, M. E. (2002). Coparenting and the transition to parenthood: A framework for prevention. Clinical Child and Family Psychology Review, 5, 173-195. doi:10.1023/a:1019695015110

Feinberg, M. E. (2003). The internal structure and ecological context of coparenting: A framework for research and intervention. Parenting, 3, 95-131. doi:10.1207/S15327922PAR0302_01

Feinberg, M. E., Kan, M. L., \& Hetherington, E. M. (2007). The longitudinal influence of coparenting conflict on parental negativity and adolescent maladjustment. Journal of Marriage and the Family, 69, 687-702. doi:10.1111/j.1741-3737.2007.00400.x

Finney, S. J., \& DiStefano, C. (2013). Non-normal and categorical data in structural equation modeling. In G. R. Hancock \& R. D. Mueller (Eds.), Structural Equation Modeling: A Second Course ( $2^{\text {nd }}$ ed.) (pp. 440-492). Charlotte, NC: Information Age.

Frascarolo, F., Dimitrova, N., Zimmermann, G., Favez, N., Kuersten-Hogan, R., Baker, J., \& McHale, J. (2009). Présentation de l'adaptation française de «l'échelle de coparentage » de McHale pour familles avec jeunes enfants [Presentation of the French adaptation of McHale's coparenting scale for families with young children]. Neuropsychiatrie de l'enfance et de l'adolescence, 57, 221-226. doi:10.1016/j.neurenf.2008.11.005

Friedman, H. P., \& Rubin, J. (1967). On same invariant criteria for grouping data. Journal of the American Statistical Association, 62, 1159-1178. doi:10.2307/2283767

Grolnick, W. S., Ryan, R. M., \& Deci, E. L. (1991). Inner resources for school achievement: Motivational mediators of children's perceptions of their parents. Journal of Educational Psychology, 83(4), 508-517. 
Hambleton, R. K. (2001). The next generation of the ITC Test Translation and Adaptation Guidelines. European Journal of Psychological Assessment, 17, 164-172. doi:10.1027//10155759.17.3.164

Harter, S. (1988). Manual for the Self-Perception Profile for Adolescents. Denver, CO: Denver University Press.

Harvey, J. H., Wells, G. L., \& Alvarez, M. O. (1978). Attribution in the context of conflict and separation in close relationships. In J. H. Harvey, W. Ickes, \& R. F. Kidd (Eds.), New directions in attribution research (Vol. 2, pp. 235-259). Hillsdale, NJ: Lawrence Erlbaum Associates.

Henry, D. B., Tolan, P. H., \& Gorman-Smith, D. (2005). Cluster Analysis in Family Psychology Research. Journal of Family Psychology, 19, 121-132. doi:10.1037/0893-3200.19.1.121

Hsiao, Y.-Y., Wu, C.-H., \& Yao, G. (2014). Convergent and discriminant validity of the WHOQOL-BREF using a multitrait-multimethod approach. Social Indicators Research, 116(3), 971-988. doi:10.1007/s11205-013-0313-z

Hu, L., \& Bentler, P. (1999). Cutoff criteria for fit indexes in covariance structure analysis: Conventional criteria versus new alternatives. Structural Equation Modeling: A Multidisciplinary Journal, 6, 1-55. doi:10.1080/10705519909540118

Jolliffe, I. T. (2002). Principal Component Analysis. New York, NY: Springer-Verlag. Kaufman, L., \& Rousseeuw, P. J. (2009). Finding groups in data: An introduction to cluster analysis. New York, NY: Wiley.

Keijsers, L., Branje, S. J. T., VanderValk, I. E., \& Meeus, W. (2010). Reciprocal effects between parental solicitation, parental control, adolescent disclosure, and adolescent delinquency. Journal of Research on Adolescence, 20, 88-113. doi:10.1111/j.1532-7795.2009.00631.x

Kenny, D. A., \& Kashy, D. A. (1992). Analysis of the multitrait-multimethod matrix by confirmatory factor analysis. Psychological Bulletin, 112(1), 165-172. doi:10.1037/00332909.112.1.165

Korelitz, K. E., \& Garber, J. (2016). Congruence of parents' and children's perceptions of parenting: A meta-Analysis. Journal of Youth and Adolescence, 45, 1973-1995. doi:10.1007/s 10964-016-0524-0

Láng, A. \& Abell, L. (2018). Relationship between interparental functioning and adolescents' level of Machiavellianism: A multi-perspective approach. Personality and Individual Differences, 120, 213-221. doi:10.1016/j.paid.2017.08.043

Laursen, B., Coy, K. C., \& Collins, W. A. (1998). Reconsidering changes in parent-child conflict across adolescence: A meta-analysis. Child Development, 69, 817-832. doi:10.1111/j.14678624.1998.tb06245.x 
Maccoby, E. E., Depner, C. E., \& Mnookin, R. H. (1990). Coparenting in the second year after divorce. Journal of Marriage and Family, 52, 141-155. doi:10.2307/352846

Mantzouranis, G., Zimmermann, G., Biermann Mahaim, E., \& Favez, N. (2012). A further examination of the distinction between dependency-oriented and achievement-oriented parental psychological control: Psychometric properties of the DAPCS with French-Speaking Late Adolescents. Journal of Child and Family Studies, 21, 726-733. doi:10.1007/s10826011-9525-5

Margolin, G., Gordis, E. B., \& John, R. S. (2001). Coparenting: A link between marital conflict and parenting in two-parent families. Journal of Family Psychology, 15, 3-21. doi:10.1037/08933200.15 .1 .3

Marsh, H. W., \& Hocevar, D. (1988). A new, more powerful approach to multitrait-multimethod analyses: Application of second-order confirmatory factor analysis. Journal of Applied Psychology, 73, 107-117. doi:10.1037/0021-9010.73.1.107

McHale, J. P. (2007). Charting the bumpy road of coparenthood: Understanding the challenges of family life. Ithaca, NY: Zero To Three.

McHale, J. P. (2010). Shared child rearing in nuclear, fragile, and kinship family systems: Evolution, dilemmas, and promise of a coparenting framework. In M.S. Schulz, M. Pruett, P.K. Kerig, \& R.D. Parke (Eds.), Strengthening couple relationships for optimal child development: Lessons from research and intervention (pp.77-94). Washington, DC: American Psychological Association.

McHale, J. P., Irace, K. (2011). Coparenting in diverse family systems. In J. P. McHale \& K. M. Lindahl (Eds.), Coparenting: A conceptual and clinical examination of family systems (pp.1537). Washington, DC: American Psychological Association.

McHale, J. P., Kuersten-Hogan, R., Lauretti, A., \& Rasmussen, J. L. (2000). Parental reports of coparenting and observed coparenting behavior during the toddler period. Journal of Family Psychology, 14, 220-236 doi:10.1037/0893-3200.14.2.220

Minuchin, S. (1974). Families and family therapy. Cambridge, MA: Harvard University Press.

Nylund, K. L., Asparouhov, T., \& Muthen, B. (2007). Decising on the number of classes in latent class analysis and growth mixture modeling: a Monte Carlo simulation study. Structural Equation Modeling, 14, 535-569. doi:10.1080/10705510701575396

Office fédéral de la statistique (OFS) (2017). Les familles en Suisse [Families in Switzerland].

Neuchâtel, Switzerland : Office fédéral de la statistique.

Office fédéral de la statistique (OFS) (2020). Langues déclarées comme principales en2018 [Main languages in 2018]. Retrieved from https://www.bfs.admin.ch/bfs/fr/home/statistiques/population/langues-religions/langues.html 
Pinquart, M., \& Teubert, D. (2015). Links among coparenting behaviors, parenting stress, and children's behaviors using the new German coparenting inventory. Family Science, 6, 201210. doi:10.1080/19424620.2015.1065284

R Development Core Team. (2014). R: A language and environment for statistical computing. Vienna, Austria: R Foundation for Statistical Computing.

Renno, P. \& Wood, J. J. (2013). Discriminant and convergent validity of the anxiety construct in children with autism spectrum disorders. Journal of Autism and Developmental Disorders, 43, 2135-2146. doi:10.1007/s10803-013-1767-1

Riina, E. M., \& McHale, S. M. (2014). Bidirectional influences between dimensions of coparenting and adolescent adjustment. Journal of Youth and Adolescence, 43, 257-269. doi:10.1007/s10964-013-9940-6

Rote, W. M., \& Smetana, J. G. (2016). Patterns and predictors of mother-adolescent discrepancies across family constructs. Journal of Youth and Adolescence, 45, 2064-2079. doi:10.1007/s10964-016-0515-1

Rouyer, V., Huet-Gueye, M., Baude, A., \& Mieyaa, Y. (2015). Presentation of the French adaptation of the Parenting Alliance Inventory: Issues in defining and measuring coparenting. Family Science, 6, 194-200. doi:10.1080/19424620.2015.1082051

Schaefer, E. S. (1965). Children's reports of parental behavior: An inventory. Journal of Consulting Psychology, 29(6), 552-557.

Scholte, R. H. J., van Lieshout, C. F. M., de Wit, C. A. M., \& van Aken, M. A. G. (2005). Adolescent personality types and subtypes and their psychosocial adjustment, Merrill-Palmer Quarterly, 51, 258-286. doi:10.1353/mpq.2005.0019

Siffert, A., Schwarz, B. \& Stutz, M. (2012). Marital Conflict and Early Adolescents' SelfEvaluation: The Role of Parenting Quality and Early Adolescents' Appraisals. Journal of Youth and Adolescence, 41, 749-763. doi:10.1007/s10964-011-9703-1

Soenens, B., Vansteenkiste, M., \& Beyers, W. (2019). Parenting adolescents. In M. H. Bornstein (Ed.), Handbook of parenting : Children and parenting (3rd ed., Vol. 1, pp. 101-167). New York, NY: Routledge.

Soenens, B., Vansteenkiste, M., \& Luyten, P. (2010). Toward a domain-specific approach to the study of parental psychological control: Distinguishing between dependency-oriented and achievement-oriented psychological control. Journal of Personality, 78, 217-256. doi:10.1111/j.1467-6494.2009.00614.X

Statistique Vaud (StatVD) (2015). Portrait des familles vaudoises [Portrait of the families of Canton de Vaud]. Renens, Switzerland: PCL Presses Centrales.

Steinberg, L., \& Silk J. S. (2002). Parenting adolescents. In M. H. Bornstein (Ed.), Handbook of 
parenting: Children and parenting (Vol. 1) (pp. 103-133). Mahwah, NJ: Lawrence Erlbaum Associates.

Teubert, D., \& Pinquart, M. (2010). The association between coparenting and child adjustment: A meta-analysis. Parenting, 10, 286-307. doi:10.1080/15295192.2010.492040

Teubert, D, \& Pinquart, M. (2011a). The coparenting inventory for parents and adolescents (CIPA): Reliability and validity. European Journal of Psychological Assessment, 27, 206-215. doi:10.1027/1015-5759/a000068

Teubert, D., \& Pinquart, M. (2011b). The link between coparenting, parenting, and adolescent life satisfaction. Family Science, 2, 221-229. doi:10.1080/19424620.2012.666655

Uliaszek, A. A. (2014). Content overlap. In Robin L. Cautin (Ed.), The Encyclopedia of Clinical Psychology. New York, NY: John Wiley \& Sons, Inc.

doi:10.1002/9781118625392.wbecp178

Van Egeren, L. A. (2004). The development of the coparenting relationship over the transition to parenthood. Infant Mental Health Journal, 25, 453-477. doi:10.1002/imhj.20019

Van Petegem, S., Antonietti, J.-P., Eira Nunes, C., Kins, E., \& Soenens, B. (2020). The relation between maternal overprotection, adolescent internalizing and externalizing problems, and psychological need frustration: A multi-informant study using Response Surface Analysis. Journal of Youth and Adolescence, 49, 162-177. doi:10.1007/s10964-019-01126-8

Van Petegem, S. V., Zimmer-Gembeck, M. J., Soenens, B., Vansteenkiste, M., Brenning, K., Mabbe, E., ... Zimmermann, G. (2017). Does General Parenting Context Modify Adolescents' Appraisals and Coping with a Situation of Parental Regulation? The Case of Autonomy-Supportive Parenting. Journal of Child and Family Studies, 26, 2623-2639. doi:10.1007/s10826-017-0758-9

Weissman, S. H., \& Cohen, R. S. (1985). The parenting alliance and adolescence. Adolescent Psychiatry, 12, 24-45.

White, J. M., Klein, D. M., \& Martin, T. F. (2014). Family theories $\left(4^{\text {th }}\right.$ ed.). Thousand Oaks, CA: Sage.

Whiteman, S. D., \& Loken, E. (2006). Comparing analytic techniques to classify dyadic relationships: An example using siblings. Journal of Marriage and Family, 68, 1370-1382. doi:10.1111/j.1741-3737.2006.00333.x

Zimmermann, G. (2010). Risk perception, emotion regulation and impulsivity as predictors of risk behaviours among adolescents in Switzerland. Journal of Youth Studies, 13, 83-99. doi:10.1080/13676260903173488 
Table 1. Sample items, Cronbach's $\alpha$ and item-total correlations of the CI-PA

\begin{tabular}{|c|c|c|c|}
\hline$\overline{\mathrm{CI}-\mathrm{PA}}$ & Sample items & Cronbach's $\alpha$ & $\begin{array}{l}\text { Item-total } \\
\text { correlation range }\end{array}$ \\
\hline \multicolumn{4}{|c|}{ Adolescent } \\
\hline $\mathrm{AD}-\mathrm{Cp}$ & If I have a problem, my parents solve it together. & .77 & $.50-.67$ \\
\hline $\mathrm{AD}-\mathrm{Cf}$ & My parents agree on whether I did something wrong or not. (r) & .66 & $.35-.53$ \\
\hline $\mathrm{AD}-\mathrm{Tr}$ & I get involved in my parents' arguments. & .80 & $.54-.70$ \\
\hline $\mathrm{AM}-\mathrm{Cp}$ & My mother speaks about my father as a good person. & .75 & $.26-.62$ \\
\hline AM-Cf & My mother is stricter than my father. & .77 & $.42-.65$ \\
\hline $\mathrm{AM}-\mathrm{Tr}$ & My mother uses me as leverage in her arguments with my father. & .86 & $.56-.80$ \\
\hline AF-Cp & My father speaks about my mother as a good person. & .79 & $.41-.66$ \\
\hline AF-Cf & My father is stricter than my mother. & .77 & $.55-.62$ \\
\hline $\mathrm{AF}-\mathrm{Tr}$ & My father uses me as leverage in his arguments with my mother. & .85 & $.55-.78$ \\
\hline \multicolumn{4}{|l|}{ Mother } \\
\hline MD-Cp & My partner and I raise our child together. & .84 & $.59-.72$ \\
\hline MD-Cf & $\begin{array}{l}\text { It is easy for my partner and I to find a shared solution for } \\
\text { problems concerning our child. (r) }\end{array}$ & .78 & $.46-.68$ \\
\hline $\mathrm{MD}-\mathrm{Tr}$ & Our child gets involved in conflicts between me and my partner. & .79 & $.47-.68$ \\
\hline MF-Cp & My partner describes me as a good mother to our child. & .84 & $.58-.71$ \\
\hline MF-Cf & My partner thinks, that I do allow our child too much. & .79 & $.52-.65$ \\
\hline MF-Tr & My partner uses our child to assert his interests against me. & .88 & $.69-.79$ \\
\hline \multicolumn{4}{|l|}{ Father } \\
\hline FD-Cp & My partner and I raise our child together. & .79 & $.52-.68$ \\
\hline FD-Cf & $\begin{array}{l}\text { It is easy for my partner and I to find a shared solution for } \\
\text { problems concerning our child. (r) }\end{array}$ & .76 & $.47-.64$ \\
\hline FD- $\mathrm{Tr}$ & Our child gets involved in conflicts between me and my partner. & .75 & $.34-.67$ \\
\hline FM-Cp & My partner describes me as a good father to our child. & .79 & $.49-.65$ \\
\hline FM-Cf & My partner thinks, that I do allow our child too much. & .76 & $.44-.64$ \\
\hline $\mathrm{FM}-\mathrm{Tr}$ & My partner uses our child to assert her interests against me. & .90 & $.75-.82$ \\
\hline
\end{tabular}

Note. $\mathrm{AD}=$ adolescent report about coparenting of the parental dyad; $\mathrm{AM}=$ adolescent report about maternal contributions to coparenting; $\mathrm{AF}=$ adolescent report about paternal contributions to coparenting; $\mathrm{MD}=$ maternal report about coparenting of parental dyad; $\mathrm{MF}=$ maternal report about paternal contributions to coparenting; $\mathrm{FD}=$ paternal report about coparenting of parental dyad; FM = paternal report about maternal contributions to coparenting; $\mathrm{Cp}=$ Cooperation; $\mathrm{Cf}=$ Conflict; $\mathrm{Tr}=$ Triangulation; $(\mathrm{r})$ : reversed item 
Table 2. Summary of CFA fit indices of the CI-PA and model comparisons (final model in bold)

\begin{tabular}{|c|c|c|c|c|c|c|c|c|}
\hline Informant & Model & $\mathrm{df}$ & YB- $\chi^{2}$ & CFI & RMSEA $(90 \% \mathrm{CI})$ & SRMR & $\begin{array}{c}\Delta \chi^{2} \\
(1 \text { vs. } 2 \mathrm{~A} / \\
2 \mathrm{~A} \text { vs. } 3)\end{array}$ & $\begin{array}{c}\Delta \chi^{2} \\
(1 \text { vs. } 2 \mathrm{~B} / \\
2 \mathrm{~B} \text { vs. } 3 \text { ) }\end{array}$ \\
\hline \multirow[t]{4}{*}{$\mathrm{AD}$} & One-factor & 54 & 222.89 & .79 & $.100(.089-.112)$ & .077 & & \\
\hline & Two-factor A & 53 & 219.83 & .90 & $.100(.089-.112)$ & .079 & 3.78 & \\
\hline & Two-factor B & 53 & 80.62 & .97 & .041 (.025-.056) & .040 & & $57.29^{*}$ \\
\hline & Three-factor & 51 & 79.02 & .97 & $.042(.026-.057)$ & .040 & $204.57^{*}$ & 1.42 \\
\hline \multirow[t]{4}{*}{$\mathrm{AM}$} & One-factor & 65 & 688.86 & .48 & $.175(.165-.186)$ & .147 & & \\
\hline & Two-factor A & 64 & 360.56 & .75 & $.122(.111-.133)$ & .102 & $62.49^{*}$ & \\
\hline & Two-factor B & 64 & 552.02 & .59 & $.156(.146-.167)$ & .135 & & $46.75^{*}$ \\
\hline & Three-factor & 62 & 178.31 & .90 & $.078(.065-.090)$ & .076 & $133.71^{*}$ & $151.30^{*}$ \\
\hline \multirow[t]{4}{*}{$\mathrm{AF}$} & One-factor & 65 & 775.67 & .36 & $.187(.177-.198)$ & .164 & & \\
\hline & Two-factor A & 64 & 417.96 & .68 & $.133(.122-.144)$ & .119 & $63.05^{*}$ & \\
\hline & Two-factor B & 64 & 454.96 & .65 & $.140(.129-.151)$ & .136 & & $56.14^{*}$ \\
\hline & Three-factor & 62 & 205.39 & .87 & $.086(.074-.098)$ & .072 & $113.93^{*}$ & $139.68^{*}$ \\
\hline \multirow[t]{4}{*}{ MD } & One-factor & 54 & 345.47 & .73 & $.132(.120-.143)$ & .094 & & \\
\hline & Two-factor A & 53 & 272.73 & .79 & $.115(.103-.127)$ & .080 & $21.74^{*}$ & \\
\hline & Two-factor B & 53 & 153.20 & .91 & $.078(.066-.090)$ & .067 & & $288.03^{*}$ \\
\hline & Three-factor & 51 & 102.45 & .95 & .057 (.043-.071) & .053 & $699.27^{*}$ & $28.39^{*}$ \\
\hline \multirow[t]{4}{*}{ MF } & One-factor & 65 & 496.15 & .57 & $.146(.137-.155)$ & .131 & & \\
\hline & Two-factor A & 64 & 357.26 & .68 & $.125(.116-.135)$ & .115 & $21.73^{*}$ & \\
\hline & Two-factor B & 64 & 390.33 & .67 & $.128(.118-.138)$ & .120 & & $19.32^{*}$ \\
\hline & Three-factor & 62 & 209.95 & .85 & .087 (.077-.098) & .081 & $94.41^{*}$ & $113.96^{*}$ \\
\hline \multirow[t]{4}{*}{ FD } & One-factor & 54 & 351.31 & .71 & $.133(.121-.145)$ & .078 & & \\
\hline & Two-factor A & 53 & 236.31 & .82 & $.105(.092-.119)$ & .063 & $33.70^{*}$ & \\
\hline & Two-factor B & 53 & 185.80 & .87 & $.090(.077-.103)$ & .066 & & $112.40^{*}$ \\
\hline & Three-factor & 51 & 104.82 & .95 & $.058(.043-.073)$ & .049 & $297.50^{*}$ & $53.00^{*}$ \\
\hline \multirow[t]{4}{*}{ FM } & One-factor & 65 & 458.64 & .56 & .139 (.130-.149) & .135 & & \\
\hline & Two-factor A & 64 & 317.87 & .72 & $.113(.103-.123)$ & .116 & $34.10^{*}$ & \\
\hline & Two-factor B & 64 & 303.70 & .73 & $.110(.100-.120)$ & .101 & & $33.66^{*}$ \\
\hline & Three-factor & 62 & 154.85 & .90 & $.069(.058-.081)$ & .075 & $94.63^{*}$ & $101.30^{*}$ \\
\hline
\end{tabular}

Notes: $\mathrm{AD}=$ adolescent report about coparenting of the parental dyad; $\mathrm{AM}=$ adolescent report about maternal contributions to coparenting; $\mathrm{AF}=$ adolescent report about paternal contributions to coparenting; $\mathrm{MD}=$ maternal report about coparenting of parental dyad; $\mathrm{MF}=$ maternal report about paternal contributions to coparenting; FD = paternal report about coparenting of parental dyad; $F M=$ paternal report about maternal contributions to coparenting; two-factor A (2A): supportive coparenting (i.e., cooperation) vs. unsupportive coparenting (i.e., conflict and triangulation); two-factor B (2B): triangulation vs. a combination of cooperation and conflict. ${ }^{*} p<.001$ 
Table 3. Means (higher scores indicate a stronger level of coparenting dimensions), standard deviations and correlations between dimensions of the CI-PA

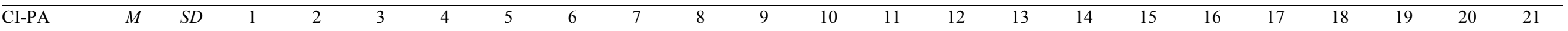

Adolescent

\begin{tabular}{|c|c|c|c|c|c|c|c|c|c|c|}
\hline 1. AD-Cp & 4.10 & .88 & 1 & & & & & & & \\
\hline 2. AD-Cf & 2.25 & .86 & $-.72^{* *}$ & 1 & & & & & & \\
\hline 3. AD-Tr & 2.14 & 1.02 & $-.50^{* *}$ & $.42^{* *}$ & 1 & & & & & \\
\hline 4. AM-Cp & 3.93 & .88 & $.64^{* *}$ & $-.54^{* *}$ & $-.34^{* *}$ & 1 & & & & \\
\hline 5. AM-Cf & 2.62 & 1.12 & $-.25^{* *}$ & $.27^{* *}$ & $.24^{* *}$ & $-.14^{*}$ & 1 & & & \\
\hline 6. AM-Tr & 1.91 & 1.04 & $-.34^{* *}$ & $.31^{* *}$ & $.48^{* *}$ & $-.23^{* *}$ & $.42^{* *}$ & 1 & & \\
\hline 7. AF-Cp & 3.95 & .92 & $.59^{* *}$ & $-.49^{* *}$ & $-.31^{* *}$ & $.82^{* *}$ & -.08 & $-.18^{* *}$ & 1 & \\
\hline 8. AF-Cf & 2.42 & 1.07 & $-.17^{* *}$ & $.15^{* *}$ & $.24^{* *}$ & $-.11^{*}$ & $-.25^{* *}$ & $.14^{* *}$ & $-.15^{* *}$ & 1 \\
\hline 9. $\mathrm{AF}-\mathrm{Tr}$ & 1.70 & .90 & $-.36^{* *}$ & $.28^{* *}$ & $.50^{* *}$ & $-.19^{* *}$ & $.30^{* *}$ & $.70^{* *}$ & $-.23^{* *}$ & $.22^{* *}$ \\
\hline
\end{tabular}

Mother

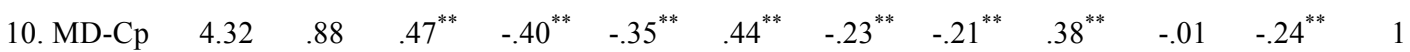

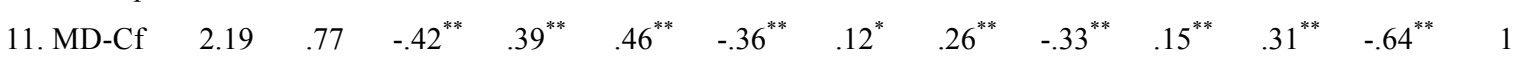

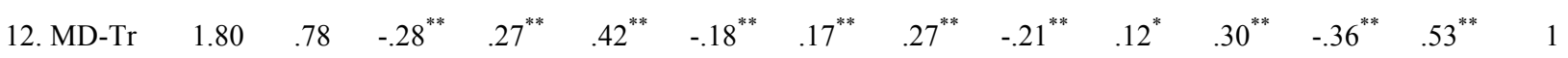

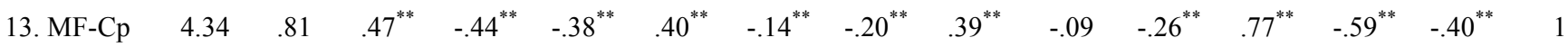

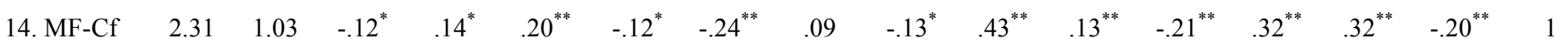

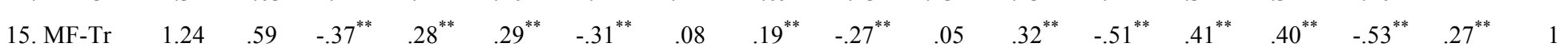
Father

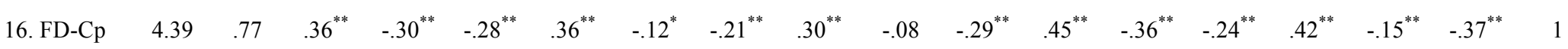

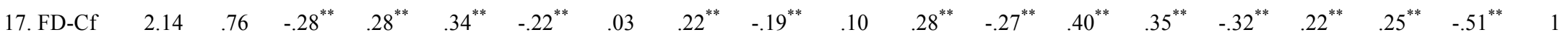

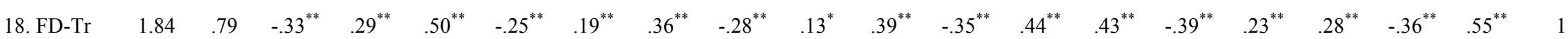
19. FM-Cp $\quad 4.45 \quad \begin{array}{lllllllllllllllllllll} & .61 & .37^{* *} & -.32^{* *} & -.31^{* *} & .37^{* *} & -.11 & -.16^{* *} & .31^{* *} & -.08 & -.24^{* *} & .48^{* *} & -.40^{* *} & -.23^{* *} & .57^{* *} & -.11 & -.44^{* *} & .67^{* *} & -.50 & -.44^{* *} & 1\end{array}$

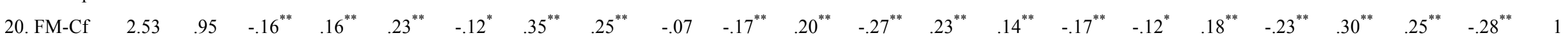

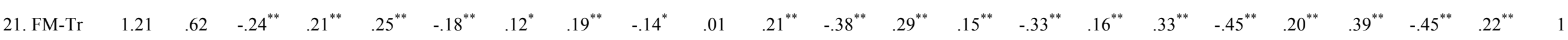

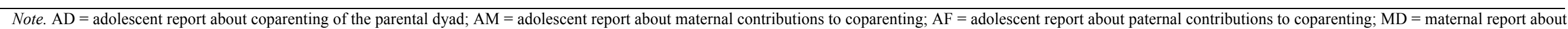
coparenting of parental dyad; $\mathrm{MF}=$ maternal report about paternal contributions to coparenting; $\mathrm{FD}=$ paternal report about coparenting of parental dyad; $\mathrm{FM}=$ paternal report about maternal contributions to coparenting; $\mathrm{Cp}=$ Cooperation; $\mathrm{Cf}=$ Conflict; $\mathrm{Tr}=$ Triangulation

$p<.01,{ }^{*} p<.05$ 
Table 4. Summary of Goodness-of-Fit Indices for coparenting MTMM models

\begin{tabular}{|c|c|c|c|c|c|c|c|}
\hline Model & YB- $\chi^{2}$ & $d f$ & CFI & RMSEA $(90 \% \mathrm{CI})$ & SRMR & AIC & $\mathrm{BIC}$ \\
\hline $\begin{array}{l}\text { Model A } \\
\text { (one-factor) }\end{array}$ & $59.59^{* *}$ & 18 & .95 & $.086(.064-.109)$ & .042 & 5874.22 & 5975.29 \\
\hline $\begin{array}{l}\text { Model B } \\
\text { (two-factor; Cp vs. Cf }+\mathrm{Tr} \text { ) }\end{array}$ & $31.29^{*}$ & 17 & .98 & $.052(.024-.078)$ & .037 & 5844.18 & 5948.98 \\
\hline $\begin{array}{l}\text { Model C } \\
\text { (two-factor; } \mathrm{Cp}+\mathrm{Cf} \text { vs. Tr) }\end{array}$ & $40.71^{* *}$ & 17 & .97 & $.067(.042-.092)$ & .032 & 5854.69 & 5959.50 \\
\hline $\begin{array}{l}\text { Model D } \\
\text { (three-factor) }\end{array}$ & 18.43 & 15 & .99 & $.027(.000-.061)$ & .025 & 5833.29 & 5945.58 \\
\hline
\end{tabular}

Table 5. Differential Goodness-of-Fit Indices for MTMM coparenting models

\begin{tabular}{lccc}
\hline Model comparisons & $\Delta \chi^{2}$ & $\Delta d f$ & $p$ value \\
\hline Model D vs. Model A & 42.88 & 3 & $<.001$ \\
Model D vs. Model B & 12.79 & 2 & $<.001$ \\
Model D vs. Model C & 23.41 & 2 & $<.001$ \\
\hline
\end{tabular}


Table 6. Correlations between dimensions of the CI-PA, parenting dimensions, self-esteem and risk-taking

\begin{tabular}{|c|c|c|c|c|c|c|}
\hline & Responsiveness & Autonomy support & $\begin{array}{l}\text { Dependency-oriented } \\
\text { psychological control }\end{array}$ & $\begin{array}{l}\text { Achievement-oriented } \\
\text { psychological control }\end{array}$ & Self-esteem & Risk-takin \\
\hline \multicolumn{7}{|l|}{$\overline{\text { CI-PA }}$} \\
\hline 1. $\mathrm{AD}-\mathrm{Cp}$ & $.42^{* *}$ & $.42^{* *}$ & $-.24^{* *}$ & $-.35^{* *}$ & $.30^{* *}$ & $-.14^{*}$ \\
\hline 2. AD-Cf & $-.44^{* *}$ & $-.41^{* *}$ & $.23^{* *}$ & $.28^{* *}$ & $-.29^{* *}$ & $.21^{* *}$ \\
\hline 3. AD-Tr & $-.29^{* *}$ & $-.33^{* *}$ & $.31^{* *}$ & $.30^{* *}$ & $-.24^{* *}$ & $.20^{* *}$ \\
\hline 4. AM-Cp & $.44^{* *}$ & $.37^{* *}$ & $-.13^{*}$ & $-.25^{* *}$ & $.27^{* *}$ & $-.15^{* *}$ \\
\hline 6. $\mathrm{AM}-\mathrm{Tr}$ & $-.16^{* *}$ & $-.27^{* *}$ & $.40^{* *}$ & $.29^{* *}$ & $-.34^{* *}$ & $.13^{*}$ \\
\hline 7. AF-Cp & $.35^{* *}$ & $.35^{* *}$ & -.11 & $-.21^{* *}$ & $.27^{* *}$ & $-.12^{*}$ \\
\hline 8. AF-Cf & -.10 & $-.19^{* *}$ & $.18^{* *}$ & $.11^{*}$ & $-.21^{* *}$ & $.17^{* *}$ \\
\hline 9. AF-Tr & -.11 & $-.16^{* *}$ & $.35^{* *}$ & $29^{* *}$ & $-.22^{* *}$ & .10 \\
\hline 10. MD-Cp & $.15^{* *}$ & $.18^{* *}$ & .03 & -.09 & .05 & -.08 \\
\hline 11. MD-Cf & $-.22^{* *}$ & $-.22^{* *}$ & .06 & $.15^{* *}$ & $-.16^{* *}$ & $.12^{*}$ \\
\hline 13. MF-Cp & $.18^{* *}$ & $.17^{* *}$ & .04 & -.06 & .08 & .02 \\
\hline 14. MF-Cf & -.06 & $-.13^{*}$ & .07 & .07 & $-.15^{*}$ & $.12^{*}$ \\
\hline 15. MF-Tr & -.07 & -.09 & -.03 & -.03 & $-.12^{*}$ & .07 \\
\hline 16. FD-Cp & $.16^{* *}$ & $.15^{* *}$ & -.05 & $-.15^{* *}$ & .08 & .05 \\
\hline 17. FD-Cf & $-.23^{* *}$ & $-.24^{* *}$ & .07 & .11 & $-.14^{*}$ & .07 \\
\hline 18. FD- $\operatorname{Tr}$ & $-.12^{*}$ & $-.14^{*}$ & $.14^{*}$ & $.14^{*}$ & $-.12^{*}$ & .10 \\
\hline 19. FM-Cp & $.18^{* *}$ & $.20^{* *}$ & -.01 & $-.14^{* *}$ & $.13^{*}$ & -.07 \\
\hline 20. FM-Cf & $-.14^{*}$ & $-.14^{*}$ & .08 & $.19^{* *}$ & -.08 & .09 \\
\hline 21. FM-Tr & .00 & -.05 & .06 & .05 & -.05 & .01 \\
\hline
\end{tabular}

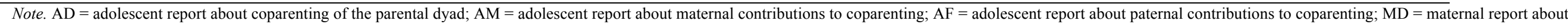

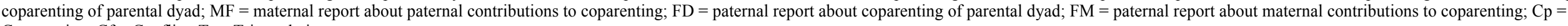
Cooperation; $\mathrm{Cf}=$ Conflict; $\mathrm{Tr}=$ Triangulation

${ }^{* *} p<.01,{ }^{*} p<.05$ 
Figure 1. Multitrait-multimethod three-factor model illustrating the relationships between methods (different informants) and traits (coparenting dimensions)

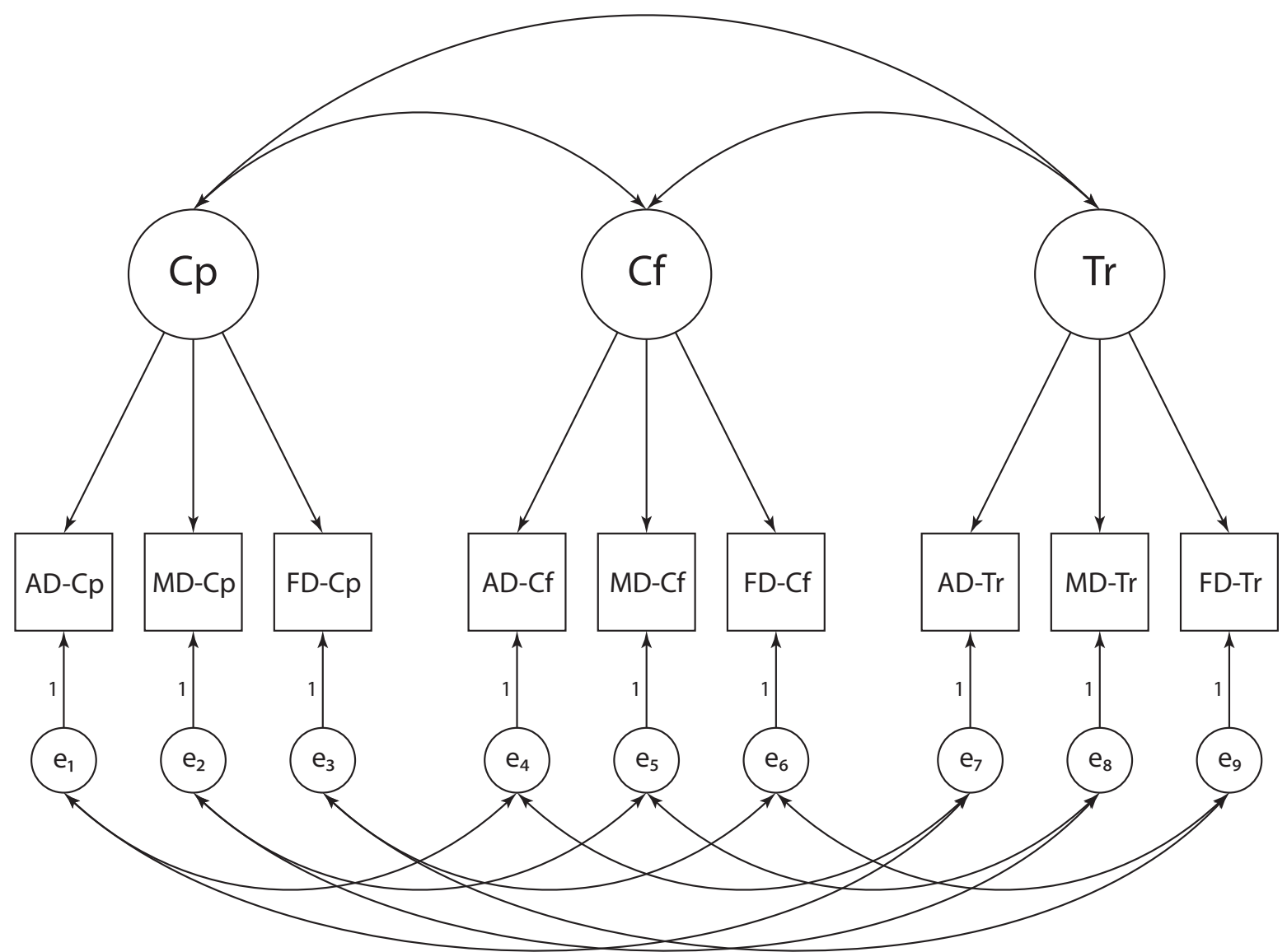

Note. $\mathrm{AD}=$ adolescent report about coparenting of the parental dyad; $\mathrm{MD}=$ maternal report about coparenting of parental dyad; $\mathrm{FD}=$ paternal report about coparenting of parental dyad; $\mathrm{Cp}=$ Cooperation $; \mathrm{Cf}=\mathrm{Conflict} ; \mathrm{Tr}=\operatorname{Triangulation}$ 
Figure 2. Final coparenting cluster solution for adolescents' respondents (Z-score on the vertical axis)

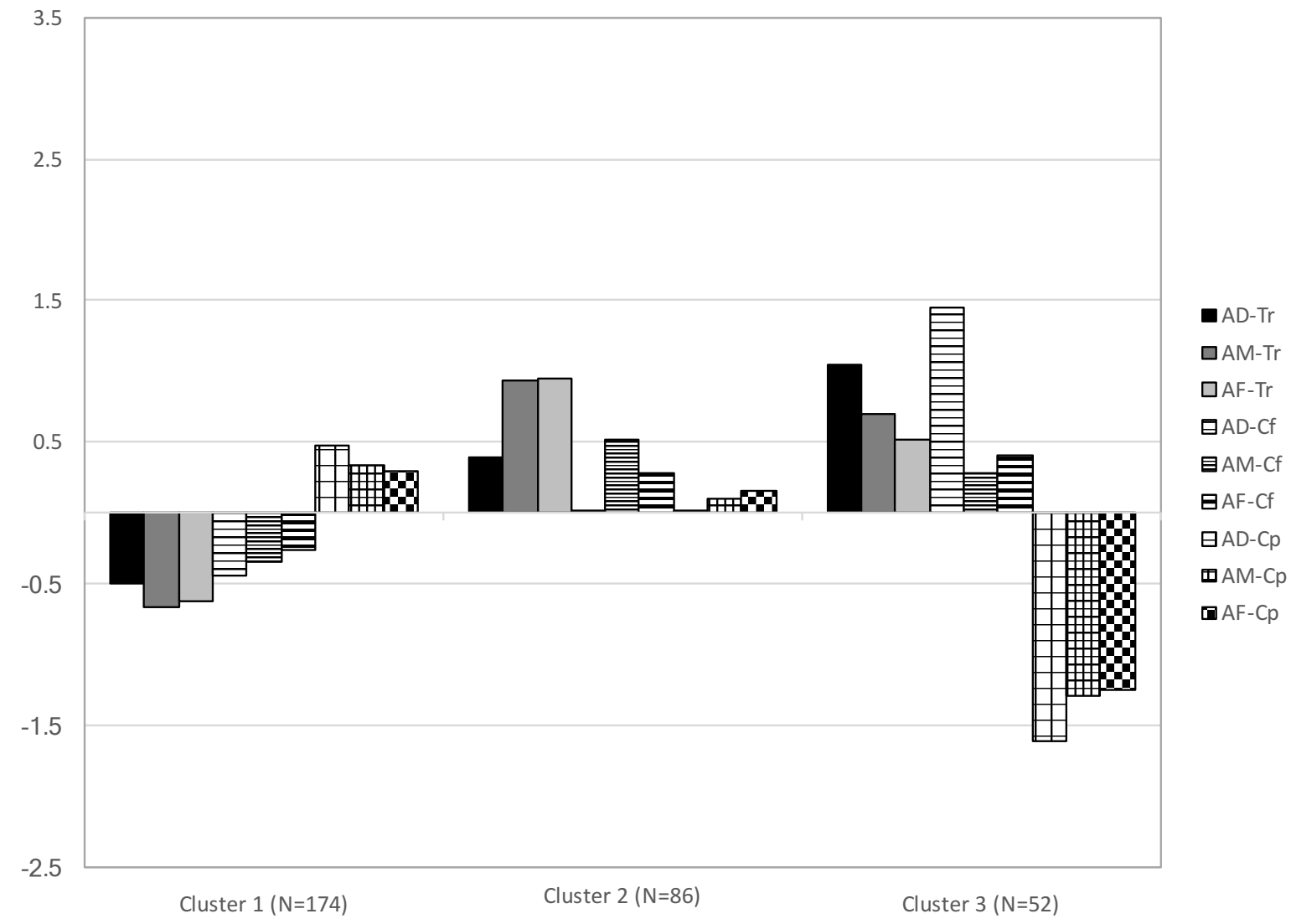

Note. $\mathrm{AD}=$ adolescent report about coparenting of the parental dyad; $\mathrm{AM}=$ adolescent report about maternal contributions to coparenting; $\mathrm{AF}=$ adolescent report about paternal contributions to coparenting; $\mathrm{Cf}=$ Conflict; $\mathrm{Tr}=\mathrm{Triangulation}$ 
Figure 3. Final coparenting cluster solution for mothers' respondents (Z-score on the vertical axis)

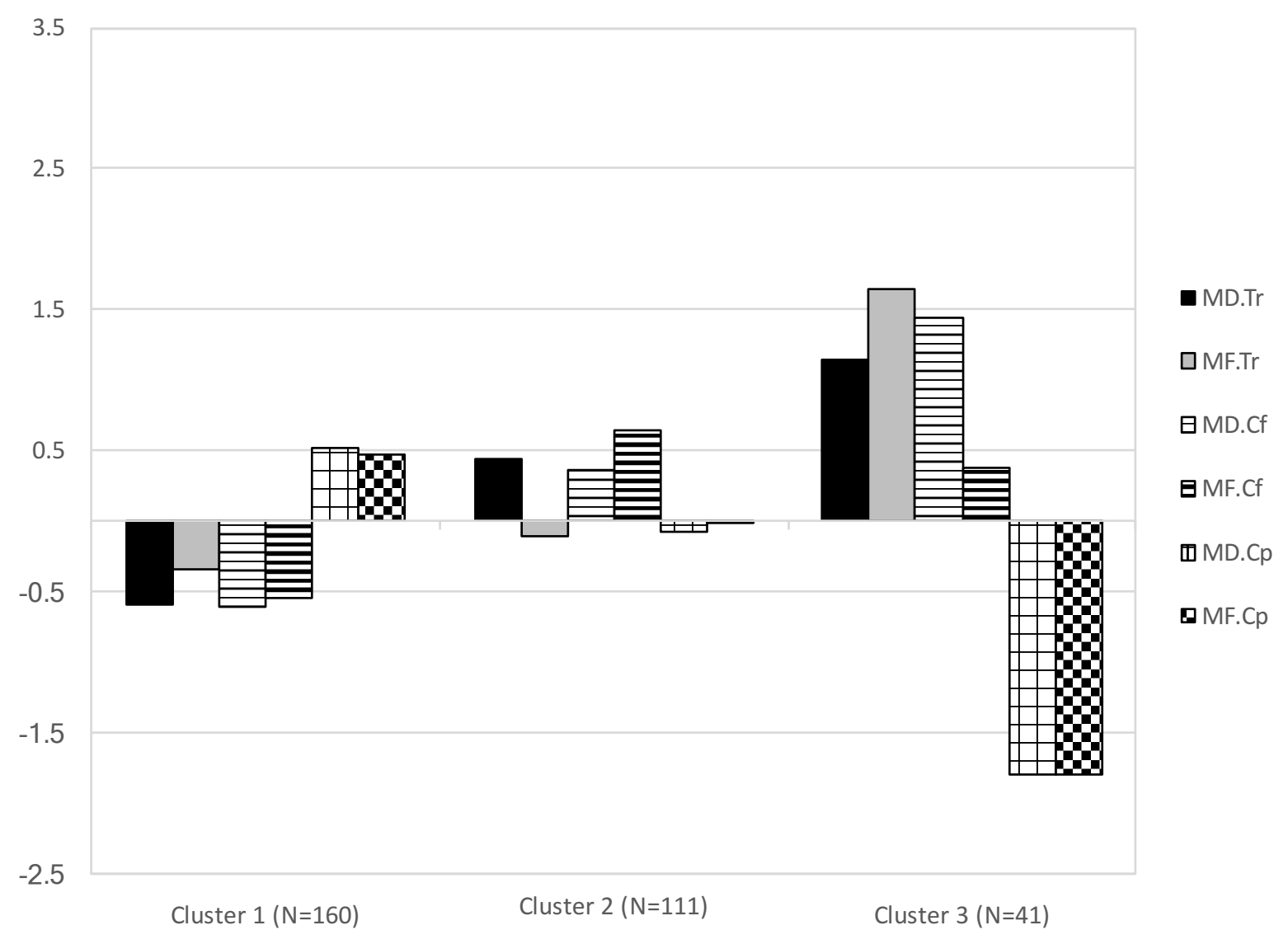

Note. $\mathrm{MD}=$ maternal report about coparenting of parental dyad; $\mathrm{MF}=$ maternal report about paternal contributions to coparenting; $\mathrm{Cp}=$ Cooperation; $\mathrm{Cf}=$ Conflict; $\mathrm{Tr}=$ Triangulation 
Figure 4. Final coparenting cluster solution for fathers' respondents (Z-score on the vertical axis)

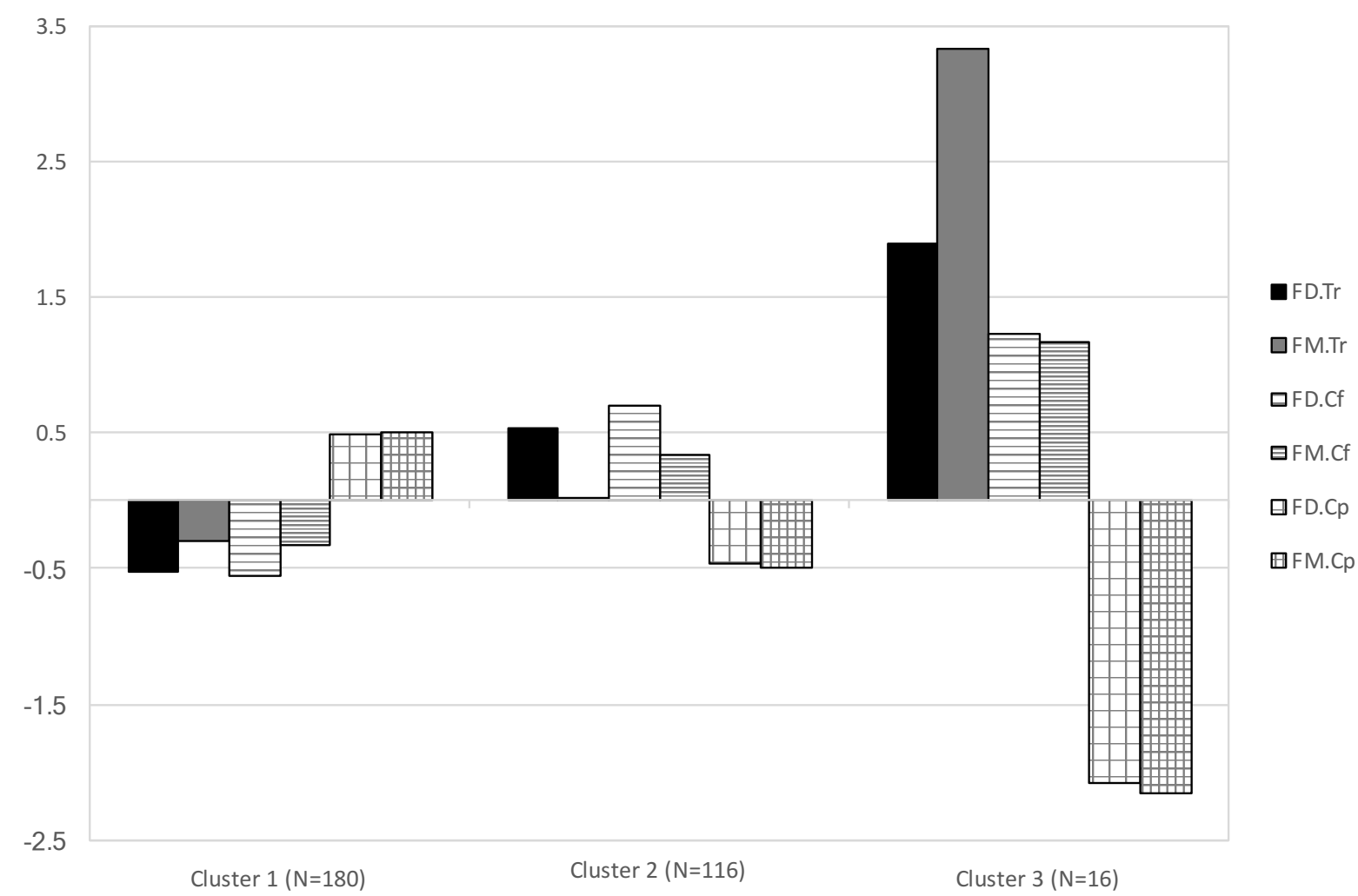

Note. $\mathrm{FD}=$ paternal report about coparenting of parental dyad; $\mathrm{FM}=$ paternal report about maternal contributions to coparenting; $\mathrm{Cp}=$ Cooperation; $\mathrm{Cf}=$ Conflict; $\mathrm{Tr}=$ Triangulation 